\title{
Promoting Educational Opportunities: long-run implications of affirmative action in college admissions*
}

\author{
Bernard Herskovic ${ }^{\dagger} \quad$ João Ramos ${ }^{\ddagger}$ \\ UCLA Anderson \\ USC Marshall
}

January 24, 2017

\begin{abstract}
This paper investigates the implications of affirmative action in college admissions for welfare, aggregate output, educational investment decisions and intergenerational persistence of earnings. We construct an overlappinggenerations model in which parents choose how much to invest in their child's education, thereby increasing both human capital and likelihood of college admission. Affirmative action improves the pool of admitted students, although it changes incentives towards educational investments. We calibrate the model to quantify affirmative action long-run effects. We find that affirmative action targeting the bottom quintile of the income distribution is a powerful policy to reduce intergenerational persistence of earnings and improve welfare and aggregate output.
\end{abstract}

JEL: I2, E24, J62.

Keywords: Affirmative Action, Intergenerational Mobility, Educational Investment.

*We would like to thank Isaac Baley, Alberto Bisin, Jaroslav Borovička, Timothy Cogley, Raquel Fernandes, Cláudio Ferraz, Chris Flinn, Elliot Lipnowski, Gaston Navarro, Debraj Ray, Stijn Van Nieuwerburgh, Gianluca Violante and seminar participants at NYU, PUC-Rio, IPEA, LACEALAMES, ESEM, and SAET. We are thankful to Data Zoom, developed by the Department of Economics at PUC-Rio, for providing the codes for accessing IBGE microdata.

† bernard.herskovic@anderson.ucla.edu

$\ddagger$ antunesr@marshall.usc.edu 


\begin{abstract}
"You do not take a person who, for years, has been hobbled by chains and liberate him, bring him up to the starting line of a race and then say, 'you are free to compete with all the others,' and still justly believe that you have been completely fair. [...] To this end equal opportunity is essential, but not enough, not enough. Men and women of all races are born with the same range of abilities. But ability is not just the product of birth. Ability is stretched or stunted by the family that you live with, and the neighborhood you live in - by the school you go to and the poverty or the richness of your surroundings. It is the product of a hundred unseen forces playing upon the little infant, the child, and finally the man." (Lyndon Johnson, 1965) ${ }^{1}$
\end{abstract}

\title{
1 Introduction
}

Affirmative action in college admissions is an important and controversial policy intended to promote educational opportunities for socially disadvantaged groups. Although its intentions are clear, the policy's effect on incentives and economic performance is subject to much debate. On the one hand, it may level the playing field, incentivizing beneficiaries of the policy to further invest in education. On the other hand, it may lower admission standards, disincentivizing beneficiaries from making educational investments. However, both supporters and critics have consistently neglected the equilibrium effects of the policy on educational investments. ${ }^{2}$

In this paper, we take equilibrium effects on educational investment into account to study the effects of affirmative action in college admissions. We focus on policies based on income and type of school attended (public or private), and we quantify their effects on welfare, inequality, and aggregate output. As one of the policy goals is to promote educational opportunities, we also study its implications for intergenerational persistence of earnings. This statistic indicates whether affirmative action promotes educational opportunities, as it measures the correlation between the income of a parent and a child. Our main finding is that affirmative action promotes opportunities for socially disadvantaged groups by reducing persistence of earnings, without hurting aggregate output. Furthermore, we show that affirmative action should be implemented on a small scale and target low-income students.

We find that affirmative action in college admissions is a tale of focus and moderation. Affirmative action is always an effective policy to reduce persistence of earnings, but its impact on economic performance is positive only if it allocates relatively few college spots to beneficiaries of the policy (moderation) and targets a specific group

\footnotetext{
${ }^{1}$ President Lyndon Johnson's commencement address at Howard University, 1965.

${ }^{2}$ For more on this debate, see Coate and Loury (1993), Moro and Norman (2003), and Fang and Norman (2006).
} 
of applicants (focus) - namely, students in the bottom of the income distribution. Furthermore, we find that affirmative action can improve efficiency even when alternative policies are in place, such as an increase in the number of college spots available or more government subsidy to public education, financed by either higher taxes or higher tuition.

Affirmative action targeting low-income students can have a positive impact on aggregate output because it makes college admissions more efficient. Without affirmative action, low-income students lack the necessary resources to invest in a successful college application and are, therefore, less likely to attend college. From a social planner's perspective, high-skilled applicants should go to college, regardless of their socioeconomic characteristics, because these applicants benefit the most from having a higher education. However, high-income students can invest heavily in education and crowd out low-income college applicants. Affirmative action tackles this source of inefficiency because it alters college demographics by admitting more high-skilled low-income applicants and fewer low-skilled high-income ones.

The educational investment decisions of both beneficiaries and non-beneficiaries are affected by affirmative action. Once implemented, the policy increases the number of college spots available to the beneficiaries, and reduces the number of college spots available to the other applicants. This changes the competitiveness of the admissions process for both groups, thus affecting the educational investment decisions of all agents. Therefore, it is imperative to endogenize the policy effects on both groups' investment incentives in order to evaluate the affirmative action policy implications.

Our framework allow us to endogenize investment decisions and human capital accumulation. $^{3}$ More importantly, it also allows us to compare affirmative actions policies against alternative policies designed to improve access to higher education, for instance by changing education financing. We develop an overlapping-generations model and numerically solve for the stationary equilibrium. Our model features four distinct generations: young child, old child, young parent and old parent.

In the model, a child is born with innate ability, which is correlated with her parents' innate ability and interpreted as the ability inherited from the parents. Young children receive investments in early education from their parents and attend either

\footnotetext{
${ }^{3}$ Our framework of human capital accumulation is in line with Ben-Porath (1967), Becker and Tomes (1979), and Restuccia and Urrutia (2004).
} 
a public or a private school. The quality of public and private schools differs on their marginal benefits of educational investments. As a combination of educational investment decisions and innate ability, each young child develops acquired ability and human capital. Acquired ability determines the likelihood of college admission, while human capital relates to future labor income. As a result of our calibration, educational investment decisions have a higher marginal impact on acquired ability than on human capital. Therefore, investment in early education affects the likelihood of college admission more than it affects the child's future labor earnings.

An agent's human capital is interpreted as her labor productivity - a combination of knowledge acquired through education and the ability to transform such knowledge into productivity. To further improve future labor earnings, older children can attend college to gain a human capital boost. Our model features two types of colleges, private and public, that differ in three dimensions. First, private and public colleges provide different human capital gains. Second, public colleges are government subsidized, whereas students in private colleges pay full tuition. Finally, public colleges have a limited number of spots and admit students based on a noisy measure of applicants' acquired ability. The supply of private college spots, however, is endogenous and meets its demand in equilibrium. ${ }^{4}$

The distinction between acquired ability and human capital is the main source of inefficiency in the model. As mentioned, college admissions are based on a noisy signal of agents' acquired ability, while earnings are based on human capital. In addition, we assume no credit market between periods, so that agents cannot borrow against future earnings in order to invest in early education and improve their children's acquired ability. ${ }^{5}$

Although colleges, based on their admissions' design, tend to admit applicants with the highest acquired ability, these applicants are not necessarily those who would benefit the most from a college education in terms of human capital gain. Specifically, wealthier parents are able to invest in their children's education, increasing the likelihood of college admission. Low-income parents, on the other hand, are credit

\footnotetext{
${ }^{4}$ The government in the model taxes labor earnings to finance the public educational systemi.e., public school and public college.

${ }^{5}$ Each period represents 16 to 18 years; hence, our no-credit restriction means that an older child cannot borrow against her adult's income. A college student cannot take a loan with a time frame longer than 16 to 18 years. However, the model features a perfect credit market within periods, and, thus, any loan with shorter terms is contemplated by the model.
} 
constrained and cannot invest as much in the education of their young children. Thus, low-income parents underinvest even when the child has high innate ability. As a result, low-income schoolchildren are less likely to attend college, leading to a socially inefficient equilibrium.

Affirmative action provides additional information to college admissions: the university can use applicants' socioeconomic characteristics to infer their unobserved innate ability and, thus, implement a more efficient admissions policy. Affirmative action increases the likelihood of college admission for preferentially-treated applicants (policy beneficiaries), and, more importantly, it may increase economic performance when targeting low-income students. In this case, the policy changes college demographics by admitting fewer high-income students with low innate ability, and more applicants with low income but higher innate ability. Furthermore, our quantitative results suggest that the policy should target the most constrained agents, focusing on the bottom of the income distribution.

Although affirmative action can make admissions more efficient, the policy impact all agents' educational investment decisions. On the one hand, affirmative action directly incentivizes the educational investments of its beneficiaries by increasing their marginal likelihood of admission; on the other hand, less competition by itself may disincentivize these investments. Likewise, non-preferentially-treated students face more competition in college admissions, which may result in higher investments since a successful college application would require such investments, or it may result in lower investments if admission is unlikely. Ultimately, the final effect on incentives depends on the magnitude of the policy. To keep educational investment incentives aligned, our quantitative results suggest that affirmative action should be moderated and not implemented on a large scale - it should allocate a relatively small fraction of college spots for the beneficiaries of the policy.

In our quantitative exercise, we consider quotas in college admissions for two types of preferentially-treated students: public-school and low-income students. Although we present a general model of human capital accumulation, our preferentially-treated group choice is motivated by the Brazilian case, where similar affirmative action policies are being implemented across the country. ${ }^{6}$ We calibrate our model to match

\footnotetext{
${ }^{6}$ In August 2012, Brazil's National Congress approved a law that implements a major-specific quota system on the admissions of all federally-sponsored universities. The quota will be based on the type of school attended (public versus private), race, and income, but focuses mainly on public
} 
the Brazilian data prior to the implementation of any affirmative action in college admissions. To quantify the importance of changes in educational investment decisions to the policy effects, we also compute the effects of the policy when households do not optimally adjust their investment decisions. Our analysis indicates that affirmative action's effect on incentives is mitigated if implemented on a small scale, with relatively few spots allocated to preferentially-treated students.

For affirmative action targeting public school students, the policy effects are close to zero for a small intervention and negative for a large one. However, holding investments constant, the policy has positive effects on economic performance variables because it improves the pool of admitted students. Once we account for endogenous changes in investment decisions, more parents enroll their children in public school to become beneficiaries of the policy. The preferentially-treated group endogenously adjusts, and affirmative action does not improve welfare, aggregate output, or intergenerational correlation of earnings.

Income-based affirmation action can have a positive impact on welfare and aggregate output in equilibrium. In this case, a policy design specifies two attributes: (i) focus, which is the income percentile that the policy targets; and (ii) intensity, which is the number of college spots allocated to preferentially-treated students. We numerically solve for two distinct optimal affirmative action policies based on income: one that maximizes the efficiency of college admissions and one that maximizes welfare, measured via the population-weighted average of agents' value function.

Efficiency-maximizing quota is more beneficial to applicants in the lower quintile of the income distribution, so that the policy improves the pool of admitted students. The policy's benefit monotonically decreases as the applicant's income increases. Efficiency-maximizing affirmative action increases aggregate output by $0.41 \%$ and improves welfare by $2.38 \%$. The efficiency-maximizing policy admits more than twice as many students from the bottom quintile of the income distribution.

The welfare-maximizing quota is even more beneficial to applicants in the lower quintiles of the income distribution. It improves the pool of admitted students and promotes income redistribution towards agents with the highest marginal utilities. Welfare-maximizing affirmative action improves welfare by $2.44 \%$, without hurting aggregate output. The welfare-maximizing policy drastically changes college demo-

schools and low-income applicants. The policy has been gradually implemented across the country, starting in 2013, and it was fully implemented in 2016. 
graphics, by tripling the number of admitted students from the bottom quintile of the income distribution.

Persistence of earnings drops by as much as 3.5\% under welfare-maximizing affirmative action and 3.2\% under the efficiency-maximizing policy. This means that a child's earnings become less correlated with her parent's income and more correlated with her own innate ability. Therefore, we find that affirmative action achieves its intentions of promoting opportunities for socially disadvantaged students.

The next subsection discusses the related literature. Section 2 shows a theoretical example, highlighting the main forces in our model, and Section 3 presents our benchmark model. Section 4 shows our calibration procedure. Section 5 reports our policy evaluation results, along with robustness exercises and the analysis of the affirmative action policy being implemented in Brazil. Section 6 presents our concluding remarks.

Related Literature Our paper adds to the literature that studies intergenerational persistence of earnings, focusing on the effects of affirmative action. Our model builds on Restuccia and Urrutia (2004). In their model, however, applicants are automatically admitted to college, while we model college admissions in detail to evaluate the economic implications of affirmative action. Restuccia and Urrutia (2004) show that about half of the observed intergenerational earnings persistence is due to investments in early education. In line with this finding, Holter (2015) estimates that investments in human capital explain nearly three quarters of intergenerational earnings persistence, and Blankenau and Youderian (2015) show that government investments in early education strongly reduce the persistence of earnings. Our paper contributes to this literature by showing that a welfare-maximizing affirmative action in college admissions reduces persistence of earnings by $3.5 \%$, without hurting aggregate output.

Our paper is also closely related to the literature that analyzes incentive implications of affirmative action in college admissions. ${ }^{7}$ Assunção and Ferman (2013) use a difference-in-differences procedure and find that affirmative action disincentivizes effort for the preferentially-treated students. While their paper focuses on short-term implications, we are concerned with long-run implications of the policy. In contrast

\footnotetext{
${ }^{7}$ Hickman (2010), Krishna and Robles (2012), Hickman (2013), Assunção and Ferman (2013), Krishna and Tarasov (2013), Kapor (2015) and Veloso (2016).
} 
to their results, our paper shows that, in the long run, preferentially-treated students do not decrease their educational investments. Hickman (2013) finds that, in the absence of affirmative action, there would be a significant drop in preferentially-treated students' college graduation rates and a large increase in income inequality. Our results are consistent with his empirical findings, as affirmative action directly affects income inequality. We show that a large-scale implementation can significantly reduce inequality, as measured by the Gini index.

Our paper is related to the literature that studies the effects of banning affirmative action in college admissions. Chan and Eyster (2003) analyze the ban in an exogenous skill distribution setting, while Fryer and Loury (2007) endogenize skill attainment and discuss at which stage of human capital formation the affirmative action policy is most effective. Finally, Epple, Romano, and Sieg (2008) study such a ban in a general equilibrium framework, in which colleges compete for students, as well. They find that banning the policy would sharply diminish the enrollment of preferentially-treated students, but the magnitude depends on which stage of human capital accumulation the policy targets. Arcidiacono (2005) empirically identifies the impact of a ban on affirmative action, concluding that such a ban would reduce the educational outcomes of the preferentially-treated group, with unclear effects on earnings. The contribution of our paper to this set of studies is to endogenize decisions towards educational incentives in a general equilibrium setting; we find affirmative action to be a sound policy to reduce persistence of earnings and improve welfare.

\section{Theoretical example}

In this section, we present a theoretical example highlighting the main mechanism in our model. We show that affirmative action can increase the aggregate human capital, by improving the quality of admitted students. This example shares several features with the benchmark model discussed in the next section - in particular, the mismatch between agents' expected human capital and their likelihood of college admission. In this example, the aggregate human capital depends primarily on the correlation between an agent's ability and her likelihood of college admissions. However, college admission is based on educational investments and therefore wealthier agents endogenously crowd out low-income applicants from college admission. This 
example is designed to highlight that income-based affirmative action changes college demographics by admitting more low-income applicants with high expected human capital and less high-income applicants with lower expected human capital. Our full specification discussed in the next section relaxes several of these assumptions, while keeping this economic mechanism unchanged.

To keep the example tractable, we assume a continuum of agents with unit measure, and each agent is identified by an income-ability pair, i.e. $(w, \pi)$. Income and ability are independent and identically distributed uniform random variables:

$$
w \sim U(0,1), \quad \pi \sim U(0,1), \quad w \perp \pi
$$

Human capital depends on agents' ability and college education. Specifically, an agent's human capital is given by $\pi$ if she does not attend college and $p \pi$ if she attends college, where $p>1$ is the human capital boost from college. ${ }^{8}$ An agent chooses whether to invest or not in education, $e \in\{0,1\}$, bearing an opportunity cost given by $\frac{e}{w}$. Investment in education affects an agent's expected human capital as it increases the probability of admission, namely $\mathrm{Pr}^{i n}$. An agent's maximization problem is given by:

$$
\max _{e \in\{0,1\}}\left(1-\operatorname{Pr}^{i n}\right) \pi+\operatorname{Pr}^{i n} p \pi-\frac{e}{w},
$$

The likelihood of admission is given by $P r^{i n}=\frac{e}{\bar{q}}$. We motivate this functional form by assuming that each applicant takes an exam, with grade given by $q=\frac{e}{\varepsilon}$, where $\varepsilon \stackrel{\text { i.i.d. }}{\sim} U(0,1)$. We assume a fixed number of college spots, $\mathcal{S} .{ }^{9}$ There is a grade-point cutoff, $\bar{q}$, such that all applicants with grades above the cutoff are admitted to college. Hence, there is a unique equilibrium grade-point cutoff such that a measure $\mathcal{S}$ is admitted to college, clearing the admission's market.

Affirmative action based on income increases the grade of low-income applicants. Applicants with income below the threshold $T \in(0,1)$ have their grade given by $q=\frac{e}{\varepsilon} B$, where $B>1$ is the grade bonus given by the policy. As a result, the probability of admission of beneficiaries of the policy becomes $\operatorname{Pr}^{i n}=\frac{e}{\bar{q}} B$. Therefore, the affirmative action is characterized by two parameters: $T$, defining the income

\footnotetext{
${ }^{8}$ In the main quantitative exercise we consider a more general human capital specification, based on Ben-Porath (1967).

${ }^{9}$ To ensure that at least a measure $\mathcal{S}$ of agents invest in education, we assume that:

$1-\mathcal{S} \geq \frac{1+\log (p-1)}{p-1}$. This assumption also ensures that $\bar{q} \geq 1$ and thus that $\operatorname{Pr}^{i n} \in[0,1]$.
} 
group benefited by the policy, and $B$, defining its magnitude.

Under affirmative action, the solution to an agent's optimization problem is given by a threshold strategy:

$$
e=1 \Leftrightarrow \pi w> \begin{cases}\frac{\bar{q}}{(p-1)}, & \text { if } w>T \\ \frac{\bar{q}}{B(p-1)}, & \text { if } w \leq T\end{cases}
$$

An agent invests in education if, and only if, the product $\pi w$ is sufficiently high. For each income level, there is an ability threshold such that an agent invests if her ability if sufficiently high.

In equilibrium, affirmative action has two distinct effects. First, there is a direct effect on low-income agents. The bonus point $B$ directly increases the probability of admissions, for a given investment choice, and also incentivizes investment by lowering the $w \pi$ threshold required to invest. Second, there is an equilibrium effect through the grade-point cutoff $\bar{q}$ affecting all agents. The policy increases the cutoff $\bar{q}$, which decreases agents' probability of admission and disincentivizes investments by increasing the $w \pi$ threshold required to invest. The combination of these two effects changes college demographics by admitting more low-income applicants with high expected human capital and less high-income applicants with lower expected human capital.

To evaluate the effects of affirmative action, we first solve for the aggregate human capital, considering a policy of magnitude $B$. Then, we focus on the marginal effect of the policy by calculating the derivative of the aggregate human capital with respect to the magnitude of the policy, evaluated at the absence of any policy. Specifically, we calculate $\left.\frac{\partial H}{\partial B}\right|_{B=1}$.

To solve for the aggregate human capital, we assume that the affirmative action policy targets an income group in which at least a positive measure agents invest in education: ${ }^{10}$

$$
T>\frac{\bar{q}_{0}}{p-1}
$$

where $\bar{q}_{0}$ is the admission's market clearing grade-point cutoff in the absence of any affirmative action policy. Specifically, $\bar{q}_{0}$ solves $\mathcal{S}=\frac{1}{\bar{q}_{0}}-\frac{1}{p-1}+\frac{1}{p-1} \log \frac{\bar{q}_{0}}{p-1}$.

The first step is to solve for the equilibrium grade-point cutoff. In equilibrium,

\footnotetext{
${ }^{10}$ If $T \leq \frac{\bar{q}_{0}}{p-1}$, then at $B=1$ affirmative action has no marginal effect, as no beneficiary of the policy invest in education.
} 
for any policy, $\bar{q}$ solves:

$$
\begin{aligned}
\mathcal{S} & =\int_{0}^{1} \int_{0}^{1} \operatorname{Pr}^{i n} d \pi d w \\
& =\frac{1}{\bar{q}}\left[\operatorname{Pr}\left(w>T \& \pi w>\frac{\bar{q}}{p-1}\right)+B \operatorname{Pr}\left(w \leq T \& \pi w>\frac{\bar{q}}{B(p-1)}\right)\right] \\
& =\frac{1}{\bar{q}}\left[\int_{T}^{1} \int_{\frac{\bar{q}}{w(p-1)}}^{1} d \pi d w+B \int_{\frac{B}{w(p-1)}}^{T} \int_{\frac{\bar{q}}{w B(p-1)}}^{1} d \pi d w\right] \\
& =\frac{1}{\bar{q}}\left[1+T(B-1)-\frac{\bar{q}}{p-1}+\frac{\bar{q}}{p-1} \log \left(\frac{\bar{q}}{B(p-1)}\right)\right] .
\end{aligned}
$$

Using the implicit function theorem, we obtain the marginal effect of increasing the policy's magnitude over the grade-point cutoff, evaluated at the absence of any policy:

$$
\left.\frac{\partial \bar{q}}{\partial B}\right|_{B=1}=\bar{q}_{0} \frac{T-\frac{\bar{q}_{0}}{p-1}}{1-\frac{\bar{q}_{0}}{p-1}}>0 .
$$

The human capital is given by:

$$
H=\int_{0}^{1} \int_{0}^{1}\left(1-P r^{i n}\right) \pi+\operatorname{Pr}^{i n} p \pi d \pi d w=\frac{1}{2}+(p-1) \int_{0}^{1} \int_{0}^{1} \operatorname{Pr}^{i n} \pi d \pi d w
$$

where

$$
\begin{aligned}
\int_{0}^{1} \int_{0}^{1} \operatorname{Pr}^{i n} \pi d \pi d w & =\frac{1}{\bar{q}}\left[\int_{T}^{1} \int_{\frac{\bar{q}}{w(p-1)}}^{1} \pi d \pi d w+B \int_{\frac{B}{w(p-1)}}^{T} \int_{\frac{\bar{q}}{w B(p-1)}}^{1} \pi d \pi d w\right] \\
& =\frac{1}{2}\left[\frac{1-T+B T}{\bar{q}}+\frac{\bar{q}}{(p-1)^{2}}-\frac{\bar{q}}{(p-1)^{2} T}-\frac{2}{p-1}+\frac{\bar{q}}{B(p-1)^{2} T}\right]
\end{aligned}
$$

Finally, the marginal effect of the policy is given by:

$$
\begin{aligned}
\left.\frac{\partial H}{\partial B}\right|_{B=1} & =(p-1)\left[\left.\frac{\partial}{\partial B} \int_{0}^{1} \int_{0}^{1} \operatorname{Pr}^{i n} \pi d \pi d w\right|_{B=1}+\left.\left.\frac{\partial}{\partial \bar{q}} \int_{0}^{1} \int_{0}^{1} \operatorname{Pr} r^{i n} \pi d \pi d w\right|_{B=1} \frac{\partial \bar{q}}{\partial B}\right|_{B=1}\right] \\
& =\frac{1}{2 T}\left(T-\frac{\bar{q}_{0}}{p-1}\right)(1-T)>0 .
\end{aligned}
$$

Given that $T \in\left(\frac{\bar{q}_{0}}{p-1}, 1\right)$, affirmative action has a positive effect on aggregate human 
capital.

This example captures a key channel through which affirmative action increases aggregate human capital: It changes the composition of admitted students, by admitting more low-income applicants with high expected human capital and less highincome applicants with lower expected human capital. However, our example has simplifying assumptions. For instance, it is a static environment, in which income and ability are exogenous and independent. Also, investments in education are discrete and have no effect on human capital, except through the probability of admission; whereas ability has no effect on admissions, except through the investment threshold decision.

In the next section, we present a more comprehensive and realistic framework. We relax the above restrictions, and study affirmative action through the lens of an overlapping generations model. Our benchmark framework features a dynamic human capital formation process, in which educational investments affect human capital both directly, by increasing future earnings, and indirectly, by increasing the probability of college admission. Our model also considers public and private educational systems, endogenous opportunity cost of educational investments, and a tax system to finance public education.

\section{Model}

\subsection{Setup}

We develop a model of four overlapping-generations based on Restuccia and Urrutia (2004). Each agent lives four periods, the first two as a child (young and old child) and the other two as an adult (young and old parent). Each generation is a continuum of measure 1, and a family unit comprises one parent and one child. At each point in time, there are two different family units: one with a young child and a young parent, and another with an old child and an old parent. Each period in the model is interpreted as a 16- to 18-year period. There is no population growth. Agents are heterogeneous in their innate ability levels; a young child is being born with an innate ability level that depends on her parent's innate ability according an autoregressive process. Decisions are made at the family level - the parent makes consumption and educational investment choices, maximizing the welfare of the family. Furthermore, 
households have access to a perfect credit market within-period, but no credit market between periods.

Young parent A particular young parent is identified by her human capital $\left(h_{y}\right)$ and her young child's innate ability $(\pi)$. The parent inelastically supplies human capital services in the labor market, and her labor income is equal to $w h_{y}$, where $w$ is the equilibrium wage rate. The government proportionally taxes labor income at rate $\tau$, and the young parent decides how to allocate her after-tax labor income between consumption $\left(c_{y}\right)$ and investment in her young child's early education $(e)$. Thus, the young parent's budget constraint is given by

$$
c_{y}+e=(1-\tau) w h_{y}
$$

We assume no credit market between periods: all the young parents' earnings are either consumed or invested in early education. However, since each period represents 16 to 18 years, the budget constraint in equation (1) implies a perfect credit market within-period.

In addition to choosing how much to invest in early education and how much to consume, a young parent also decides whether her child attends public or private school. The early educational investment $(e)$ is transformed into an effective early educational investment $(\hat{e})$, which depends on the type of school attended according to

$$
\hat{e}= \begin{cases}\alpha(e+g) & \text { if } s=p u \text { (public school) } \\ e & \text { if } s=p r \text { (private school) }\end{cases}
$$

where $s$ indicates the type of school attended; $\alpha \geq 0$ captures the quality difference between public and private school; and $g \geq 0$ is a government transfer. This specification accommodates public and private schools with differences in quality depending on the value of $\alpha$.

According to equation (2), if the child attends public school, private and public investments in education are perfect substitutes; however, the return to investments in education depend on the type of school attended. As a result of our calibration, $\alpha$ is less than one. Hence, if a young child goes to public school, she receives a government subsidy $g$, but early educational investments face lower marginal returns. In contrast, a private school has a higher marginal return to educational investments, 
but no government subsidy. As a result, the choice between public and private school depends on how much investment in education a child receives. For low educational investments - i.e., low $e$ - the benefit of early education expenditure is higher in the public school. For higher investments, the private school has a higher benefit. An interpretation for this is that, in a public school, a parent has less control over what and how her child learns. Any further investments to her education must be done after school hours, when the child is tired, making investments less efficient.

A young child builds acquired ability $(\hat{\pi})$ by combining innate ability and effective early education investment, according to

$$
\hat{\pi}=\pi \hat{e}^{\gamma}
$$

where $\gamma \in[0,1]$ measures the elasticity of acquired ability with respect to educational investments. ${ }^{11}$ We interpret acquired ability as the knowledge that a child acquires up until high school. It is a combination of how smart a child is (innate ability), and how much there was to be learned in the first place (educational investment).

Finally, the human capital of the young parent increases linearly when she becomes an old parent. This captures a life-cycle profile of earnings, and the human capital of a parent evolves according to

$$
h_{o}=\xi h_{y}
$$

where $\xi \geq 1$ is a life-cycle parameter and $h_{o}$ is the human capital of the young parent in the subsequent period.

To simplify our notation, let $x_{y}=\left(h_{y}, \pi\right)$ be the state variable of the young and $x_{o}=\left(h_{o}, \pi, \hat{\pi}, s\right)$ be the state variable of the old parent. ${ }^{12}$ Formally, in the optimization problem, a young parent chooses how much to consume, how much to invest in early education, and the type of school attended:

$$
V_{y}\left(x_{y}\right)=\max _{c_{y} \geq 0, e \geq 0, s \in\{p u, p r\}} u\left(c_{y}\right)+\beta V_{o}\left(x_{o}\right)
$$

subject to equations (1), (2), (3), and (4). The function $V_{y}(\cdot)$ is the value function

\footnotetext{
${ }^{11}$ This specification is in line with Restuccia and Urrutia (2004).

${ }^{12}$ The investment in early education is not a state variable because it can be obtained using equation (3), given $\pi$ and $\hat{\pi}$.
} 
of the young parent; $u(\cdot)$ is the utility function of the family; and $\beta$ is a discounting parameter. The function $V_{o}(\cdot)$ is the value function of the old parent, which we discuss next.

Old parent Similar to a young parent, an old parent chooses how to allocate her family labor income between consumption and investment in college education. Specifically, an old parent chooses whether or not to have her child apply to college, and, therefore, her value function is defined as

$$
V_{o}\left(x_{o}\right)=\max \left\{V_{o}^{\text {not apply }}\left(x_{o}\right), V_{o}^{\text {apply }}\left(x_{o}\right)\right\}
$$

where $V_{o}^{\text {not apply }}(\cdot)$ is the value of not applying, and $V_{o}^{\text {apply }}(\cdot)$ is the expected value of applying to college.

A central point of this decision is how attending college will affect her child's income. In the model, income is proportional to human capital, which depends on early educational investment and on innate ability. Another feature of the human capital formation is how college affects human capital. The two types of colleges in the model, private and public, differ in the cost of enrollment and in quality. That is, private and public college affect human capital formation differently.

Specifically, human capital formation is described by

$$
h_{y}^{\prime}= \begin{cases}\pi \hat{e}^{\psi} & \text { if no college } \\ \bar{p} \pi \hat{e}^{\psi} & \text { if public college } \\ \underline{p} \pi \hat{e}^{\psi} & \text { if private college }\end{cases}
$$

where $\underline{p}$ and $\bar{p}$ are the human capital gain from attending private and public college, respectively, and $\psi \in[0,1]$ is the elasticity of human capital in adulthood with respect to investments in early education. This human capital formation process is consistent with Ben-Porath (1967), Becker and Tomes (1979), and Restuccia and Urrutia (2004).

The specification of human capital formation implies that returns to college education increase with early educational investments and innate ability. The intuition behind this assumption is that both early educational investments and innate ability help the student to learn from college courses and translates college coursework into 
productive human capital. In our calibrated model, public colleges increase human capital more than private ones do. This, however, is not an assumption of our model and is, rather, a result of the calibration. ${ }^{13}$ For this reason, we describe the model assuming that $\bar{p}>\underline{p}>1$.

Given the human capital formation process, we further specify the value function of an old parent. If a child does not apply to college, then she immediately joins the labor market, inelastically supplying her human capital services. Thus, under no college education, the value of not applying is

$$
\begin{aligned}
V_{o}^{\text {not apply }}\left(x_{o}\right)= & \max _{c_{o} \geq 0} u\left(c_{o}\right)+\beta \mathbb{E}_{\pi^{\prime}}\left[V_{y}\left(x_{y}^{\prime}\right)\right] \\
& \text { s.t. } \\
& c_{o}=(1-\tau)\left(w h_{o}+w h_{y}^{\prime}\right) \\
& h_{y}^{\prime}=\pi \hat{e}^{\psi}
\end{aligned}
$$

where the first constraint is the budget constraint and the second specifies the human capital of the old child according to equation (6). The budget constraint includes the post-tax income from all family members combined. The continuation value of the old parent is the expected value function of her own child as a young parent in the next period. This expectation is over the innate ability distribution of the old parent's grandchild, which follows an autoregressive process,

$$
\log \left(\pi^{\prime}\right)=\rho \log (\pi)+\sigma_{\pi} \varepsilon_{\pi}
$$

The random variable $\varepsilon_{\pi}$ is an i.i.d. standard normal. Parameter $\rho$ captures the persistence of innate ability between distinct generations, and $\sigma_{\pi}$ captures the noisiness of this process.

If a child applies to college, the outcome of her application is random. The probability of college admission depends primarily on applicants' acquired ability, and college applicants with higher acquired ability are more likely to be admitted. In addition, the likelihood of college admission might also depend on the type of high school attended and even on the parent's income, according to the affirmative

\footnotetext{
${ }^{13}$ Such difference in quality between public and private universities is consistent with the Brazilian case. For example, all top ten Brazilian universities are public, and, among the top 20, only two are private, using the ranking from the main Brazilian newspaper Folha de São Paulo. Assunção and Ferman (2013) also make the case for high-quality higher education being offered mostly by public institutions in Brazil.
} 
action implemented. The probability of admission is given by $q\left(\hat{\pi}, s, h_{o}\right)$, and it is an equilibrium object that we discuss in depth in the next subsection, along with a description of the college admissions market. Taking the probability function as given, the expected value of applying to college is a combination of the value if admitted, $V_{o}^{\text {admitted }}$, and the value if not admitted, $V_{o}^{\text {not admitted: }}$

$$
V_{o}^{\text {apply }}\left(x_{o}\right)=q\left(\hat{\pi}, s, h_{o}\right) V_{o}^{\text {admitted }}\left(x_{o}\right)+\left[1-q\left(\hat{\pi}, s, h_{o}\right)\right] V_{o}^{\text {not admitted }}\left(x_{o}\right) .
$$

If an old child's college application is successful, she may go to either a private or a public college, which differ in costs and human capital gains. However, public college is preferred over private college because it is cheaper and implies a greater human capital gain according to our calibration results. For this reason, if an old child is admitted to college, the old parent value function is described as

$$
\begin{aligned}
V_{o}^{\text {admitted }}\left(x_{o}\right)= & \max _{c_{o} \geq 0} u\left(c_{o}\right)+\beta \mathbb{E}_{\pi^{\prime}}\left[V_{y}\left(x_{y}^{\prime}\right)\right] \\
& \text { s.t. } \\
& c_{o}=(1-\tau)\left[w h_{o}+w h_{y}^{\prime}(1-\eta-b)\right] \\
& h_{y}^{\prime}=\bar{p} \pi \hat{e}^{\psi}
\end{aligned}
$$

where the first constraint specifies the budget constraint, and the second defines the human capital of the old child, according to equation (6). Parameter $\eta$ represents the time spent in college, and $b$ captures the time spent applying to college. Both $\eta$ and $b$ represent the opportunity costs associated with a college education since the old child can work only a fraction $1-\eta-b$ of that period. The cost of a public college education is not factored into the budget constraint because it is fully subsidized by the government. This assumption, however, can be relaxed by assuming that the government finances only a fraction of the tuition rather than bearing the entire cost. Our quantitative and qualitative results are robust to this change.

If an old child is not admitted to a public college, then she may still attend a private college. ${ }^{14}$ Conditional on the child not being admitted to the public college,

\footnotetext{
${ }^{14}$ We assume that all college applicants are automatically admitted to a private college. According to Brazilian college data (2008 INEP report, Tables 7, 9 and 11), there are nearly seven times more students applying to public college than public college spots available. However, for a private college, the ratio of applicants to private college spots is about 1.3 . Moreover, only $5 \%$ of the public college spots are unfilled, while $50 \%$ of the private college spots are unfilled. Based on these data, we assume that no minimum admission score is needed to attend a private college. These data
} 
an old parent chooses between enrolling her child in private college $(z=1)$ or not $(z=0)$. The old parent's optimization problem if her child is not admitted to a public college is, therefore, given by

$$
\begin{aligned}
V_{o}^{\text {not admitted }}\left(x_{o}\right)= & \max _{c_{o} \geq 0, z \in\{0,1\}} u\left(c_{o}\right)+\beta \mathbb{E}_{\pi^{\prime}}\left[V_{y}\left(x_{y}^{\prime}\right)\right] \\
& \text { s.t. } \\
& c_{o}+a z \eta=(1-\tau)\left[w h_{o}+w h_{y}^{\prime}((1-z)(1-b)+z(1-\eta-b))\right] \\
& h_{y}^{\prime}=\left[(1-z) \pi \hat{e}^{\psi}+z \underline{p} \pi \hat{e}^{\psi}\right]
\end{aligned}
$$

where $a$ represents the tuition cost per unit of time. Again, while the government subsidizes public college tuition, the agent bears the full tuition cost of a private college. Even though credit and savings markets are absent from the model, a single budget constraint per period implies a perfect credit market within-period. Given the interpretation of 16 to 18 years per period, an old child can use the family's income until her $32^{\text {nd }}-36^{\text {th }}$ birthday to repay any student loan she takes to go to college.

Admissions We model college admissions as a competitive market in which applicants compete for college spots. As the result of an old child's application, the college observes a noisy signal of her acquired ability. This signal is interpreted as her application score or her grade on the admission exam, and it is defined by

$$
\log (\mathcal{P})=\log (\hat{\pi})+\sigma_{p} \varepsilon_{p}
$$

where $\varepsilon_{p}$ is an i.i.d. standard normal, and $\sigma_{p}$ is the noisiness of admissions.

The measure of potential applicants is one, which includes all old children, while the measure of spots available at the public college is given by parameter $\mathcal{S}$. Given the number of college spots available, the public college admits applicants with the highest score $(\mathcal{P})$ until all the spots are filled. Thus, the probability of public college admissions is the probability of being among the top $\mathcal{S}$ applicants according to the admission score. By the law of large numbers, there is a unique grade point cutoff, say $\bar{q}$, such that every applicant with $\mathcal{P} \geq \bar{q}$ is admitted. The cutoff $\bar{q}$ is the price that clears the admissions market.

are from a report by the National Institute for Educational Research at the Brazilian Ministry of Education (INEP/MEC 2008 report) 
Affirmative action In our model, affirmative action in college admissions changes the likelihood of a successful college application by conditioning it on the applicant's income or on the type of high school attended. The affirmative action policies studied in this paper are college quotas for a particular preferentially-treated group. If affirmative action is implemented, preferentially-treated students have a different grade point cutoff from other applicants. The cutoff grade for the preferentially-treated applicants is, of course, less than or equal to the other applicants' cutoff.

In our model, quotas are equivalent to giving bonus points to the preferentiallytreated applicants. We show that for every equilibrium with quotas, there is an equilibrium with bonus points that results in the same allocation. Conversely, for every equilibrium with bonus points, there is an equilibrium with a quota that results in the same allocation. This is a theoretical result of the model, and both proposition and proof are detailed in the Appendix. This result allows us to study the effects of quotas on college admissions by implementing bonus points instead of quotas. ${ }^{15}$ When the policy is implemented, preferentially-treated applicants have a bonus point added to their application score. Specifically, the admissions score becomes

$$
\log (\mathcal{P})= \begin{cases}\log (\hat{\pi})+\sigma_{p} \varepsilon_{p} & \text { if not preferentially-treated } \\ \log (\hat{\pi})+\log \left(\mathcal{P}_{\text {bonus }}\right)+\sigma_{p} \varepsilon_{p} & \text { if preferentially-treated }\end{cases}
$$

where $\mathcal{P}_{\text {bonus }}$ are extra points given to preferentially-treated applicants, as specified by the policy. The magnitude of such bonuses defines the intensity of the policy, as more points given imply that more college spots are allocated to preferentiallytreated applicants.

We study affirmative action for two distinct preferentially-treated groups: publicschool versus low-income applicants. When affirmative action targets low-income applicants, the policy specifies both the bonus points that preferentially-treated applicants receive (intensity) and the income group considered (focus).

Production There is one representative firm that hires human capital $(H)$ to produce consumption goods using a linear constant returns to scale production function,

\footnotetext{
${ }^{15}$ The main reason to use bonus points is that solving for the equilibrium under bonus points is computationally less intensive than under quotas.
} 
$f(H)=A H$. Hence, the firm's problem is given by:

$$
\max _{H \geq 0} f(H)-w H
$$

\subsection{Equilibrium}

We use the following equilibrium concept to solve the model.

Definition. A Stationary Recursive Competitive Equilibrium is a set of value and policy functions, wage $w$, government expenditure in early education g, grade point cutoff $\bar{q}$, distributions $\mu_{y}\left(h_{y}, \pi\right)$ and $\mu_{o}\left(h_{o}, \pi, \hat{\pi}\right)$ over the agents' states such that (i) agents maximize: given equilibrium prices, young and old parents, as well as the representative firm, optimize; (ii) markets clear: human capital, output and admissions markets clear; (iii) government budget is balanced; and (iv) distribution over the state space is stationary.

The human capital market clears when the aggregate human capital equals the representative firm's demand for human capital. ${ }^{16}$ The resource constraint is given by

$$
Y=C_{y}+C_{o}+E+F+G
$$

where $C_{y}$ and $C_{o}$ are the aggregate consumption of the young and old parents; $E$ is the aggregate expenditure on early education; $F$ is the aggregate expenditure on college education (both public and private); and $G$ is the aggregate government expenditure on early education.

Since not all young children attend public school, we have $G=\zeta g$, where $\zeta$ is the measure of students in public school. Finally, the government budget being balanced implies that

$$
\tau Y=\zeta g+a \mathcal{S} \eta
$$

where the total amount of tax collected by the government $(\tau Y)$ finances both investments in early education $(\zeta g)$ and subsidized public college $(a \mathcal{S} \eta)$.

\footnotetext{
${ }^{16}$ Aggregate human capital is the sum of the human capital of all agents working: the old child's generation, as well as the young and the old parents' generations. If an old child applies and/or attends college, then she works only a fraction of the period.
} 


\subsection{Affirmative action mechanism}

A young parent invests in early education to increase the human capital of her child. Educational investments increase human capital directly, according to equation (6), and indirectly by increasing the likelihood of college admission. Low-income parents, however, do not have the resources to optimally invest in their child's early education. As a result, low-income students are crowded out from the college admissions market and the equilibrium is inefficient. Affirmative action can mitigate this inefficiency by admitting more preferentially-treated applicants and reducing equilibrium crowding out.

A successful policy improves the pool of admitted students by reducing equilibrium crowding out, without disincentivizing educational investments. In Section 5, we show that a policy targeting applicants in the bottom of the income distribution increases aggregate output and improves welfare if implemented to a small magnitude (small bonus). The small magnitude guarantees that the policy does not heavily affect educational investment incentives, while the preferentially-treated group choice is made to include the most constrained agents, allowing the policy to, in fact, improve the pool of admitted students.

We can interpret affirmative action as additional information provided to college admissions offices. In the model, admissions are based on acquired ability, under the assumption that the admissions office does not have information regarding applicants' innate ability. Introducing affirmative action in college admissions implies that the university acquires more information regarding students' socioeconomic status. If affirmative action targets low-income students, then applicants must disclose their income - or at least their income quintile - to the university. In this case, income is additional information that the admissions office can use. The university may use applicants' income information along with their acquired ability signal to infer their innate ability and estimate their future human capital. Therefore, the implementation of affirmative action provides the university with a plethora of information and potentially increases admissions efficiency, as the university has more information on which to base their admissions criteria. 


\section{Calibration}

We numerically solve our model for the stationary recursive competitive equilibrium, as described in the Appendix. Some parameters are calibrated directly from the data or from the literature, while others have to be calibrated by targeting related moments from the data. In our calibration, we use Brazilian data prior to the implementation of any affirmative action in college admissions. ${ }^{17}$

We assume that agents have CRRA preference, $u(c)=\frac{c^{1-\sigma}-1}{1-\sigma}$, with a risk aversion of $\sigma$. We calibrate this parameter at 1.5, which is a reasonable parameter value considering several estimates from the literature (e.g., Restuccia and Urrutia 2004). The discount $\beta$ is calibrated at 0.52 , which is equivalent to 0.96 per year considering that each period is equivalent to 16 years.

The life-cycle parameter $\xi$ represents the increase in human capital from young to old adulthood. This parameter has to be estimated using panel data; however, there are no such data available for Brazil. For this reason, we calibrate $\xi$ at 1.12, based on PSID estimates. ${ }^{18}$ The marginal productivity of labor $(A)$ is normalized to 1, without loss of generality.

In the model, each period represents 16 years, and we assume that the time spent in college is four years $(\eta=4 / 16)$ and the time spent applying to college is one year $(b=1 / 16)$. To calibrate the measure of public college spots $(\mathcal{S})$, we use estimates from the Brazilian National Household Survey (PNAD) data. In 2004, $17 \%$ of adults between the ages of 18 and 28 were enrolled in college or had already earned a higher degree. This fraction does not vary much with the age group considered, ${ }^{19}$ which means that, in the model, a measure 0.17 of young children should go to either a public or a private college in equilibrium. To calibrate the measure of public college spots, we need the fraction of college students attending public institutions. We learn

\footnotetext{
${ }^{17}$ Affirmative action in college admissions was first implemented in Brazil in 2004/2005 at University of Brasilia (UnB), followed by Federal University of Bahia (UFBA) and other public universities in subsequent years.

${ }^{18}$ Restuccia and Urrutia (2004) estimate the average earnings of a 49-64-year-old person in the labor force who has a college degree, relative to those of a 33-48-year-old person with the same qualifications. They use the 1990 PSID and estimate this life-cycle parameter at 1.12. Using the 2004 Brazilian National Household Survey, PNAD (Pesquisa Nacional por Amostra de Domicílios), we find a wage ratio of 1.23 between the two groups. However, PNAD is not panel data, and it is not possible to compare the same individual along her life-cycle. The estimation using the Brazilian data does not fully capture the life cycle parameter $\xi$ in the model.

${ }^{19} \mathrm{We}$ considered ages between 18 and $24 / 26 / 28 / 30 / 32$, and the respective fractions were between $16.3 \%$ and $17.3 \%$.
} 
from the Brazilian educational census that $28 \%$ of total college enrollment was in public institutions of higher education in $2004 .^{20}$ Thus, the measure of public spots is calibrated at $\mathcal{S}=0.048$, which is $28 \%$ of 0.17 .

Finally, the tax rate, $\tau$, is directly calibrated from the data. It represents the government expenditures on education (primary, secondary and tertiary) over GDP, which was $4 \%$ in 2004, according to the World Bank. Next, we discuss the remaining parameters, which are calibrated by simultaneously matching moments from the data.

\subsection{Calibration targets}

The remaining nine parameters are calibrated to simultaneously match the following nine moments from the data: (i) standard deviation of log earnings; (ii) intergenerational correlation of earnings; (iii) fraction of applicants; (iv) aggregate college expenditures relative to GDP; (v) early education expenditures relative to GDP; (vi) college wage premium; (vii) fraction of students in private colleges; (viii) fraction of low-income students in public colleges; and (ix) fraction of students in public schools. Table 1 reports all these moments in the model and in the data, as well as their related parameters.

In the model, the parameter $\sigma_{\pi}$ affects innate ability and earnings dispersion and, hence, is chosen to match the standard deviation of log earnings. The intergenerational correlation of earnings measures the persistence of earning between two generations of the same family. Specifically, it is the slope coefficient of regressing the log earnings of the old parent on the log earnings of her child as a young parent. For the US, the intergenerational correlation of earnings is roughly 0.40 , using the PSID data (Solon 1992). For developing economies, there are no estimates using panel data to the best of our knowledge. ${ }^{21}$ In our calibration, we target the intergenerational correlation of earnings at $40 \%$, which is accurately measured from the panel data. The parameter $\rho$ affects innate ability and earning persistence and is chosen to match the intergenerational correlation of earnings. Our calibration of $\rho$ at

\footnotetext{
${ }^{20}$ Data statistics were taken from the INEP (2008) report. In 2004, there were 4,163,733 students enrolled in institutions of higher education, 1,178,328 of whom were in public institutions.

${ }^{21}$ Corak $(2006,2010)$ computes a correlation of $58 \%$ for Brazil but uses parents' estimated earnings based on occupation and education. Corak (2010) shows that persistence of earnings varies significantly across countries, from $15 \%$ in Denmark to $67 \%$ in Peru. However these estimates are based on estimated parents' earning rather than on panel data.
} 
0.25 is consistent with the the estimation made by Holter (2015), as well as with the calibration of Restuccia and Urrutia (2004), and Blankenau and Youderian (2015).

\title{
Table 1: Calibration Targets
}

\begin{abstract}
This table reports all calibration targets along with their respective parameters in the model. The first two columns provide the model parameters, and the last three columns provide their respective moment both in the data and in the model. The standard deviation of log earnings (row i) uses the Brazilian National Household Survey (PNAD 2004) data; the intergenerational correlation of earnings (row ii) is from Restuccia and Urrutia (2004). The fraction of applicants is computed based on the 2008 report made by the National Institute for Educational Research at the Brazilian Ministry of Education (INEP/MEC 2008) using 2004/8 data. Educational expenditure moments (rows iv-v) use data from the Brazilian Household Budget Survey (POF 2004) and the World Bank (2004). Finally, we compute the college wage premium (row vi), the measure of students in private college (row vii), the fraction of low-income students in public college (row viii), and the fraction of students in public school (row ix) using PNAD 2004. A detailed description of the construction of these moments is provided in the main text. Low-income students in row (viii) refer to those in the second quintile of the income distribution.
\end{abstract}

\begin{tabular}{clllll}
\hline \hline & \multicolumn{2}{l}{ Parameters } & Moments & Data & Model \\
\hline i & $\sigma_{\pi}$ & 0.83 & Standard deviation of log earnings & 0.95 & 0.96 \\
ii & $\rho$ & 0.25 & Intergenerational correlation of earnings & 0.40 & 0.40 \\
iii & $\sigma_{p}$ & 1.40 & Fraction of applications & 0.34 & 0.32 \\
iv & $a$ & 1.17 & College expenditure relative to GDP & 0.014 & 0.014 \\
v & $\psi$ & 0.18 & Early education expenditure relative to GDP & 0.060 & 0.064 \\
vi & $\bar{p}$ & 2.10 & College wage premium & 2.76 & 2.77 \\
vii & $\underline{p}$ & 1.15 & Fraction of students in private college & 0.12 & 0.12 \\
viii & $\bar{\gamma}$ & 0.80 & Fraction of low-income students in public college & 0.07 & 0.08 \\
ix & $\alpha$ & 0.50 & Fraction of students in public school & 0.87 & 0.86 \\
\hline \hline
\end{tabular}

Based on the Brazilian educational census, the ratio between applicants and public college spots is 7 . Since we have a measure of $4.8 \%$ of public college spots, the measure of applicants is targeted at 34\%. The noise of the admissions exam $\left(\sigma_{p}\right)$ directly affects this moment. For instance, if there is no noise in the admissions process and the acquired ability is perfectly observed, then only students who are admitted would apply to college. Thus, we calibrate $\sigma_{p}$ to match the measure of applicants at 0.34 .

We target early education expenditures over GPD at $6 \%$ by varying the concavity of the human capital capital formation function (parameter $\psi$ ), and we match college education expenditures over GPD at $1.4 \%$ by varying the cost of college education (parameter $a$ ). According to the Brazilian Household Budget Survey $(\mathrm{POF})^{22}$ for 2003-2004, the average fraction of after-tax income spent on education was $4.08 \%$. According to World Bank data, the Brazilian government spent $4.01 \%$ of GPD on

\footnotetext{
${ }^{22}$ Pesquisa de Orçamento Familiar.
} 
education in the same period. Using the average Brazilian tax revenue rate for the period $(15.9 \%)$, the total investment in education was approximately $7.44 \%$ of total output. Still, according to the World Bank, $18.92 \%$ of total education expenditures are allocated to higher education in Brazil, and, therefore, Brazilian investments in education are $1.4 \%$ in higher education and $6 \%$ in early education relative to GDP.

We compute the college wage premium as the average wage conditional on having a college degree relative to not having a college degree. In 2004, the college wage premium was 2.76 for college graduates between ages 30 and 48 relative to those with a only high school degree. The public college human capital gain $(\bar{p})$ drives the college wage premium, so we calibrate $\bar{p}$ to match the college wage premium.

The number of students who attend private college depends on the human capital gains that the college provides. If the private college human capital gain $(\underline{p})$ is low, only a few students will be willing to attend private college, but as the benefit increases, more students will be willing to attend. As discussed before, a measure of 0.17 students attend college, with 0.048 going to a public college and the remaining 0.122 to a private college. The measure in public college is directly calibrated by the parameter $\mathcal{S}$, and we calibrate $\underline{p}$ to match the measure of students in private college.

To calibrate the elasticity of acquired ability with respect to early educational investments, we target the fraction of public-school students in the $40^{\text {th }}$ percentile of the income distribution, which is $7 \%$ for the Brazilian case. ${ }^{23}$ Although public colleges are tuition free, when their quality is higher than that of the private college, then, in equilibrium, high-income applicants crowd out low-income applicants by investing more heavily in early education and endogenously making it harder to get into college. Therefore, public colleges will have more or fewer low-income students depending on how much early education increases the likelihood of college admission. For example, if $\gamma$ is high, then high-income parents are able to increase the likelihood of admission, and, as a result, low-income students are crowded out of public colleges. Thus, we calibrate $\gamma$ to match the fraction of low-income students attending a public college.

\footnotetext{
${ }^{23}$ Using PNAD data, $7 \%$ of the public college students are in the bottom $40 \%$ of the income distribution. To compute these moments of the college income distribution, we use the 2002 PNAD so that we do not include students in private college with a ProUni scholarship. The affirmative action policy to be implemented in Brazil focuses on the first quintile of the income distribution, for which we also have a good fit. The fraction of public college students in bottom quintile is $2.8 \%$ in the data and $3.2 \%$ in the model.
} 
The fraction of students in public high schools was $87 \%$ in 2004, and, in the model, this fraction is directly affected by public school inefficiency $(\alpha)$. If $\alpha$ is low (high), then public school has a lower (higher) return and more (fewer) young parents would enroll their child in a private school. Thus, we calibrate $\alpha$ to match the fraction of young children in public schools.

\section{Policy evaluation}

In this section, we compare the steady-state equilibrium of our calibrated model with and without affirmative action. We study the implications of affirmative action policies for aggregate output, intergenerational correlation of earnings, inequality (Gini index), and welfare. We also compute the policy effects, keeping the investment decisions constant-i.e., holding the investment policy function unchanged. This allows us to disentangle policy effects due to changes in investment decisions from effects due to a better or worse college admissions rule. Welfare is measured as a population-weighted average of agents' value functions. Aggregate output measures the efficiency of college admissions because it is equal to the aggregate human capital in the economy, and, as a result, an affirmative action policy that leads to higher aggregate human capital (output) improves admissions efficiency. Thus, both welfare and aggregate output are important measures of the economic performance of affirmative action policies. In addition, persistence of earnings evaluates whether the policy effectively promotes educational opportunities for socially-disadvantaged students.

Subsections 5.1 and 5.2 consider two different preferentially-treated groups: students from the public school system and low-income students. When holding educational investments constant, policies that focus on these two different groups have similar implications; however, endogenizing investment decisions, income-based policies have different effects than those based on the type of school attended. Subsection 5.3 discusses two distinct optimal policies: one that maximizes the efficiency of admissions and another that maximizes welfare. Finally, subsection 5.4 presents several robustness exercises, and subsection 5.5 evaluates the affirmative action currently being implemented in Brazil. 
Figure 1: Affirmative Action for Public School

This figure reports the effects of bonus points added to the admission exam grade on old children that attended public school. The effects on welfare, aggregate output, inequality, and intergenerational correlation of earnings are plotted against the left axis, and the fraction of students in the preferentially-treated group attending public colleges is plotted against the right axis. The social welfare considered is simply the sum of all agents' value function.

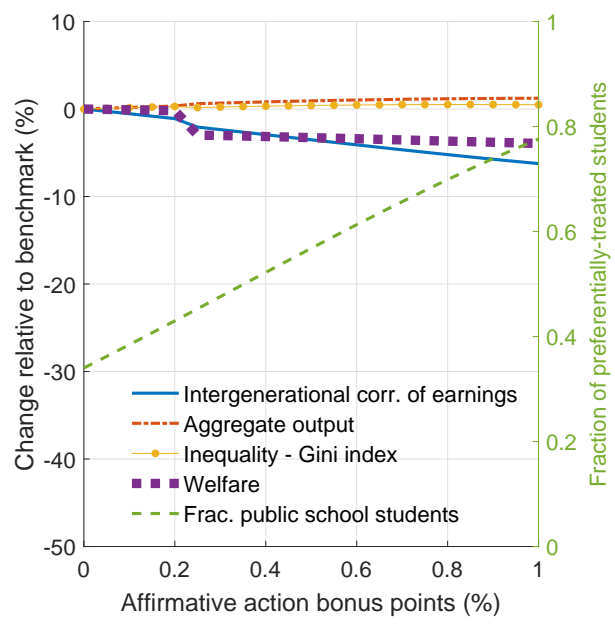

(a) Fixed Educational Investments

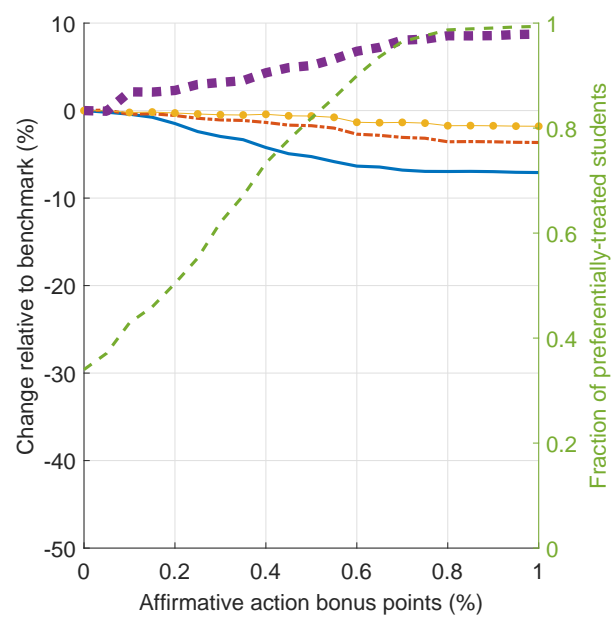

(b) Equilibrium Effects

\section{$5.1 \quad$ Public school}

In this subsection, we evaluate affirmative action in college admissions targeting public school applicants. Under such a policy, all applicants who attended public school as a young child receive a bonus score on their admissions exam and, therefore, are more likely to be admitted to a public college. Figure 1 plots the impact of the policy on different economic variables by varying the magnitude of the bonus points until it is equivalent to a $100 \%$ quota. Panel (a) reports policy effects by keeping educational incentives unchanged, while panel (b) includes all equilibrium effects. In both panels, changes to economic variables relative to our benchmark calibration are plotted against the left axis, while the fraction of preferentially-treated students in public colleges is plotted against the right axis.

When holding educational investment decisions constant, affirmative action affects only the pool of admitted students. As a result, the policy makes admissions more efficient and increases aggregate output. In addition, affirmative action significantly reduces persistence of earnings. It increases the likelihood of college admission for public school applicants - who are poorer and more constrained than private school applicants - effectively breaking the correlation between the earnings 
of parents and their offspring.

However, in equilibrium, the policy effects are considerably different, as is illustrated by the difference between panels (a) and (b). The curve plotting the fraction of preferentially-treated students attending college is much steeper in equilibrium because the policy gives bonus points to students from public schools, thus incentivizing parents to enroll their children in public school. Parents who, before the policy, would choose to enroll their child in a private school to further invest in her education would now choose to enroll their child in a public school and reduce investments. Switching from a private to a public school increases the likelihood of college admission, even though public schools handle large educational investments inefficiently. As a result, the preferentially-treated group endogenously adjusts to the policy in equilibrium, mitigating the benefits observed in panel (a). An increase in the number of students attending public schools results in lower investments in education, which offset the potential efficiency gains from the policy. This is an equilibrium backlash that limits the effects of the policy on equilibrium variables.

When all equilibrium effects are taken into account, affirmative action increases welfare but decreases aggregate output when implemented on a large scale. Nevertheless, a narrower policy improves welfare without significantly decreasing output. Implementing a narrower policy improves the pool of admitted students, while keeping incentives for investing in education roughly unchanged. Implementing a broader policy changes incentives for investing in education, which results in more students attending public school, lower educational investments, and, therefore, output and welfare losses. The policy successfully increases the innate ability level but significantly reduces investment. Therefore, our results suggest that affirmative action targeting public school applicants is not an effective policy to significantly increase either aggregate output or welfare.

\subsection{Low income}

The policy maker needs to consider two characteristics of affirmative action targeting low-income applicants: intensity and focus. Policy intensity establishes the bonus points that preferentially-treated applicants receive, while focus determines the income group to receive the benefit. In what follows, we discuss results for a policy that targets different quintiles of the income distribution. Figures 2 and 3 show the 
Figure 2: Affirmative Action for Low Income - 20 th Percentile

This figure reports the effects of bonus points added to the admission exam grade for old children whose parents have low income $\left(20^{t h}\right.$ percentile). The effects on welfare, aggregate output, inequality, and intergenerational correlation of earnings are plotted against left axis. The fraction of students in the preferentially-treated group attending public college is plotted against the right axis, which is the quota magnitude for the bonus points. Social welfare considered is simply the sum of all agents' value function.

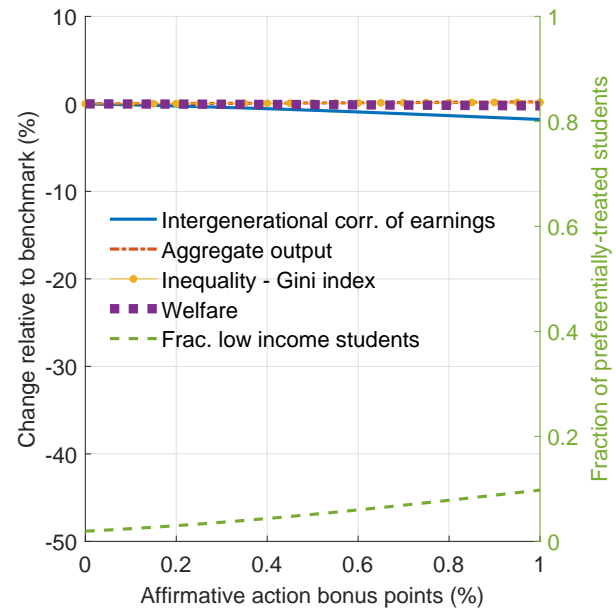

(a) Fixed Educational Investments

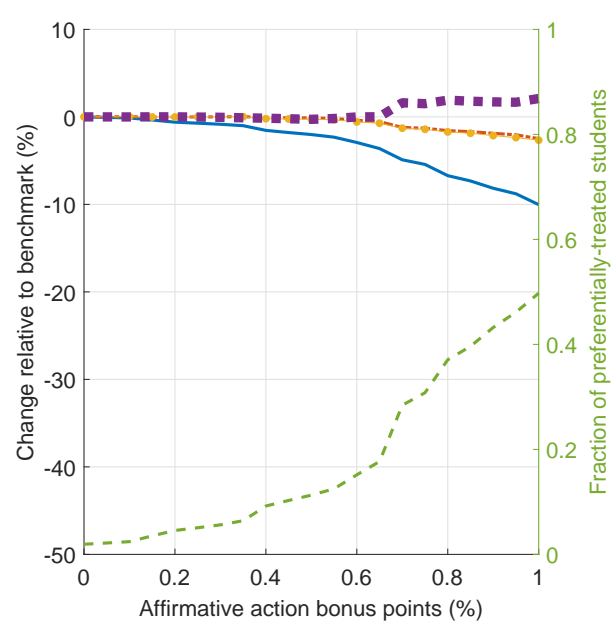

(b) Equilibrium Effects

effects of the policy for different intensity levels. Figure 2 displays results for the policy targeting the first quintile of the income distribution, and Figure 3 the policy targeting the middle quintile.

Keeping educational investment decisions constant, we find that as low-income applicants receive more bonus points (intensity), aggregate output increases, and welfare decreases along with intergenerational correlation of earnings. This is clearly illustrated by Panel (a) in Figure 3. By targeting low-income applicants, the policy benefits college applicants who would have been crowded out of college admission in equilibrium, resulting in more efficient admissions and higher aggregate output. Efficiency also induces positive sorting in admissions, increasing inequality measured by the Gini index. At the same time, welfare declines, as households do not adjust their investment decisions. These effects are more pronounced if the policy targets the middle-income quintile.

The equilibrium results are in sharp contrast to policy effects when investment decisions are held constant. Affirmative action targeting low-income applicants disincentivizes non-preferentially-treated applicants from investing in education as policy intensity increases, and beneficiaries can crowd out non-beneficiaries of the policy 


\section{Figure 3: Affirmative Action for Low Income - $60^{\text {th }}$ Percentile}

This figure reports the effects of bonus points added to the admission exam grade for old children whose parents have low income $\left(60^{t h}\right.$ percentile). The effects on welfare, aggregate output, inequality, and intergenerational correlation of earnings are plotted against left axis. The fraction of students in the preferentially-treated group attending public college is plotted against the right axis, which is the quota magnitude for the bonus points. Social welfare considered is simply the sum of all agents' value function.

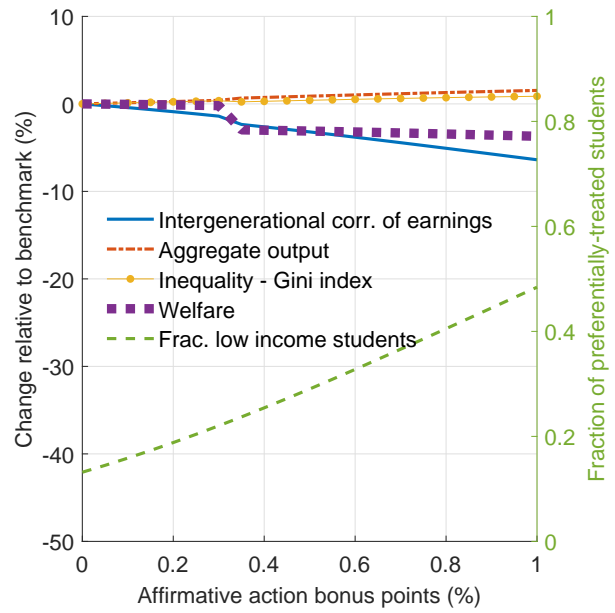

(a) Fixed Educational Investments

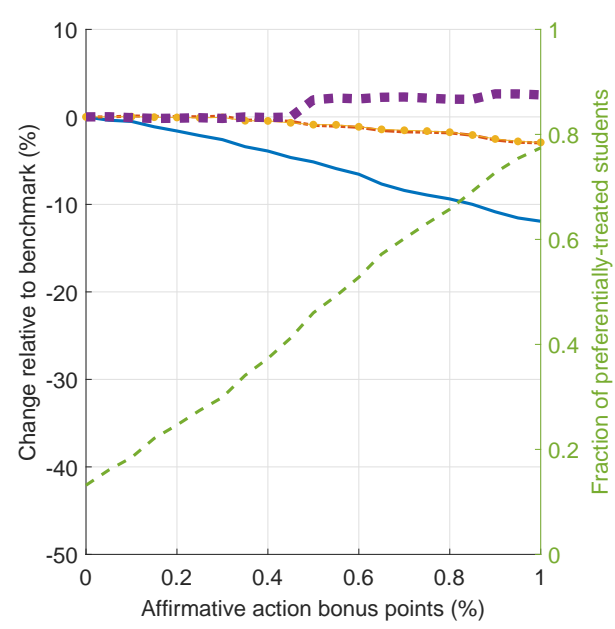

(b) Equilibrium Effects

from attending public colleges. This is a result of fiercer competition in the admissions market, as the policy reduces the number of spots available to non-beneficiaries of the program. Lower educational investments from the non-preferentially-treated students is an equilibrium backlash of the policy, resulting in lower aggregate output as policy intensity increases. Panel (a) in Figures C.1 and C.2 in the Appendix plots the average investment in early education among admitted students against affirmative action bonus points, for policies targeting different income groups. ${ }^{24}$ These graphs clearly show that investments in early education decline with policy intensity; however, they do not decrease much when bonus points are close to zero. Therefore, a small-scale policy can improve admissions efficiency and increase aggregate output, without reducing educational investments.

In addition, Panel (b) in Figures C.1 and C.2 in the Appendix shows that the average innate ability of admitted student initially increases, suggesting more efficient admissions for small-scale policies. However, average innate ability starts to decline as policy intensity increases. Persistence of earnings, on the other hand,

\footnotetext{
${ }^{24}$ Early education investments among public school students is almost entirely from nonbeneficiaries of the policy, as low-income families invest almost zero in early education.
} 
decreases with policy intensity for all the income groups considered because it increases the likelihood of college admissions for low-income applicants, which reduces intergenerational persistence of earnings.

Our quantitative results suggest that the income group targeted by the policy (focus) has different implications for welfare and efficiency. An unfocused policy (bottom 60\%, Figure 3) seems to be better for preventing a decrease in output, while a focused one (bottom 20\%, Figure 2) is more successful at increasing welfare and reducing persistence of earnings. On the one hand, since an unfocused policy targets applicants who would have been crowded out of college admission in equilibrium, thus it is more effective at improving admissions efficiency and aggregate output. A focused policy, on the other hand, targets the most constrained families and, therefore, is more effective at increasing welfare and reducing persistence of earnings.

Changes in welfare are particularly interesting when low-income applicants receive more bonus points. Welfare effects are a result of changes both in the efficiency of college admissions and in the income redistribution. As discussed earlier, a narrower policy improves the pool of admitted students and increases aggregate output. In this case, the entire economy produces more consumption goods, and welfare improves. As more bonus points are allocated to low-income applicants, the equilibrium effects become stronger, and the policy changes educational investment incentives, resulting in lower aggregate output and potentially lower welfare. These two distinct effects are offsetting in small-scale policies, and we do not observe significant changes in welfare. However, if the policy strongly benefits low-income applicants, then there is a redistributional effect that improves welfare. Low-income families have high marginal utility, while high-income families have low marginal utility. Thus, by allocating more college spots to low-income applicants, the policy improves welfare by redistributing resources towards families with high-marginal utility.

Our results indicate that affirmative action has meaningful implications for aggregate output and intergenerational persistence of earnings. In the next subsection, we study the efficiency-maximizing and welfare-maximizing affirmative action policy based on income. 
Table 2: Optimal Affirmative Action

This table reports the effect of optimal affirmative action policies on persistence of earnings, aggregate output, income inequality (Gini index), and welfare. Column (1) reports the result for the affirmative action policy that maximizes aggregate human capital. Column (2) reports the affirmative action policy that maximizes welfare without decreasing aggregate human capital. We numerically solve for the optimal policies based on income quintiles.

efficiency maximizing welfare maximizing

\begin{tabular}{lcc} 
& $(1)$ & $(2)$ \\
\hline Aggregate output change (\%) & 0.41 & 0.38 \\
Welfare change (\%) & 2.38 & 2.44 \\
Persistence of earnings change (\%) & -3.23 & -3.49 \\
Gini index change (\%) & -0.09 & -0.13 \\
\hline
\end{tabular}

\subsection{Optimal affirmative action}

Welfare analysis in our framework features a trade-off between efficiency of college admissions and income redistribution. Because the marginal utility of low-income families is higher than that of high-income families, income redistribution towards a uniform distribution induces welfare gains. However, more efficient college admissions maximize aggregate human capital (output) by admitting college applicants with the highest post-college human capital. Thus, efficiency gains makes the economy more productive, but it also induces increased income dispersion.

We numerically compute two optimal affirmative action policies. First, we numerically solve for affirmative action that maximizes efficiency of college admissionsthat is, the bonus-point structure that maximizes aggregate human capital and, therefore, aggregate output. Second, we compute the policy that maximizes welfare, without hurting aggregate output. Based on our results from Section 5.1, affirmative action targeting public school applicants seems to be an ineffective policy; hence, we solve for optimal affirmative action based on income information alone. We solve for optimal policies targeting different income quintiles differently, as if a policy maker could observe which income quintile applicants belong to but not the income itself. ${ }^{25}$

Table 2 reports the results of our numerical optimization. The efficiency-maximizing affirmative action increases aggregate output by $0.41 \%$, while decreasing intergenerational persistence of earnings by $3.23 \%$. This policy improves welfare measured as

\footnotetext{
${ }^{25}$ The main reason for restricting the policy to condition on income quintiles is to keep the numerical optimization problem numerically less intense.
} 
Figure 4: Public College Income Distribution and Affirmative Action

This figure reports the fraction of students attending public college from each income quintile. We plot the income distribution under three different scenarios: without affirmative action, efficiency-maximizing affirmative action, and welfare-maximizing affirmative action.

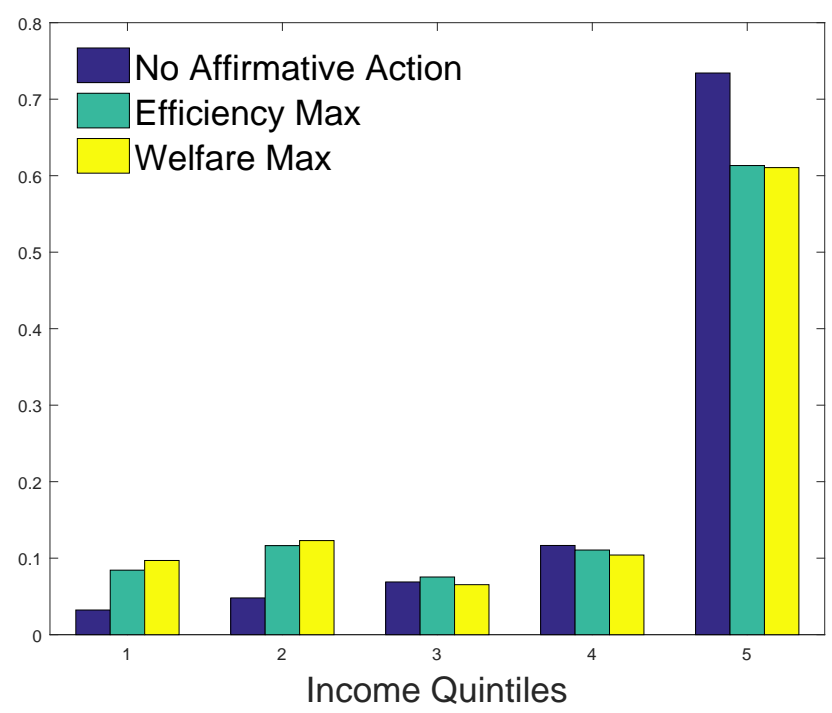

the sum of all agents' utility. Column (2) shows the policy that maximizes welfare without decreasing aggregate output. Such a policy improves welfare by $2.44 \%$ and decreases persistence a earnings by $3.49 \%$. Thus, affirmative action is a powerful policy to improve welfare and promote educational opportunities at the aggregate level, effectively breaking persistence of earnings between the different generations of the same family.

The optimal policies implement different quotas based on income. Figure 4 compares the income distribution of applicants admitted to public college under the optimal policies. Both optimal policies significantly admit more students from the lower quintiles and fewer applicants from the top quintiles. On the one hand, the efficiency-maximizing policy is a more moderated policy, with fewer bonus points to low-income applicants in order to improve the pool of admitted students, without disincentivizing educational investments. On the other hand, the welfare-maximizing policy focuses heavily on applicants in the first quintile of the income distribution, because it targets the most constrained families.

Figure 4 shows that both optimal policies change college demographics significantly. For example, the welfare-maximizing policy admits 15\% more students from the bottom quintile than the efficiency-maximizing policy, and $200 \%$ more than if 
there were no affirmative action. Most of the college income distribution changes caused by affirmative action comes from changes in the fraction of students from the first and last quintiles. Both optimal policies decrease the fraction of students from the last quintile and increase the fraction of students from first quintile. The efficiency-maximizing policy is more moderated, while the welfare-maximizing policy strongly reshapes college demographics.

\subsection{Robustness}

In this subsection, we show that affirmative action in college admissions still improves welfare and increases aggregate output, even when other alternative policies are implemented. We also show that our results are robust to changes in the benchmark parametrization.

\subsubsection{Alternative policies}

In this subsection, we verify the economic implications of alternative educational policies and show that affirmative action further improves welfare and increases efficiency. We consider the following four alternative policies: (i) improve the quality of the admissions' signal by setting $\sigma_{p}=1$ and reducing the measure of applicants by $26 \%$; (ii) increase government investments in early education by increasing taxes to $5 \%$, which captures the recent increase in educational investments made by the Brazilian government; (iii) eliminate public college subsidies so that the government can further invest in early education without raising taxes; ${ }^{26}$ and (iv) increase the number of available public college spots by $10 \%$ (e.g., we set $\mathcal{S}=0.0528$ ) to capture the recent increase in the number of public college spots at government-sponsored Brazilian universities.

These alternative policies do not entirely address the core inefficiency tackled by affirmative action. Affirmative action can improve welfare and aggregate output even with these alternative policies in place. We numerically solve for the optimal

\footnotetext{
${ }^{26}$ We solve our model for a world in which the public college student has to bear the entire cost of a college education. In this case, all labor taxes collected by the government are invested in early education, and the budget constraint of the old parent when the old child goes to college (equation 7) becomes

$$
c_{o}+a \eta=(1-\tau)\left[w h_{o}+w h_{y}^{\prime}(1-\eta-b)\right] .
$$
}


Table 3: Alternative policies with optimal affirmative action

\begin{abstract}
This table reports the effect of optimal affirmative action policies on aggregate output, welfare, persistence of earnings, and inequality measured by Gini index. We consider four distinct alternative policies. First, we consider a world in which the college admissions signal is more precise by setting $\sigma_{p}=1$. Second, we consider an increase in government investments in early education, financed by taxes, by setting $\tau=0.05$. Third, we implement tuition in public college, and, due to budget balance, the government invests more in early education using the revenue from tuition. Finally, we increase the number of public college spots by $10 \%$. We numerically solve the optimal affirmative under each alternative policy, and we report percentage changes relative to an economy without affirmative action. Panel A reports the affirmative action that maximizes aggregate output, while Panel B reports the policy that maximizes welfare without decreasing aggregate output.
\end{abstract}

\begin{tabular}{|c|c|c|c|c|}
\hline \multirow[b]{2}{*}{ Alternative policy } & \multicolumn{4}{|c|}{$\begin{array}{c}\text { Efficiency maximizing policy } \\
\text { (\% change in addition to alternative policy) }\end{array}$} \\
\hline & $\begin{array}{c}\text { output } \\
\text { (1) }\end{array}$ & $\begin{array}{l}\text { welfare } \\
(2)\end{array}$ & $\begin{array}{c}\text { earnings } \\
\text { persistence } \\
(3)\end{array}$ & $\begin{array}{c}\text { Gini } \\
\text { index } \\
(4)\end{array}$ \\
\hline \multicolumn{5}{|c|}{ Panel A: Efficiency maximizing policy } \\
\hline Better admissions's signal & 0.43 & 0.11 & -1.88 & 0.41 \\
\hline Higher tax to finance pub. sch. & 0.40 & 0.65 & 0.72 & 0.24 \\
\hline College tuition to finance pub. sch. & 0.29 & 0.46 & -0.72 & 0.35 \\
\hline More pub. college spots & 0.64 & 2.97 & -2.97 & 0.06 \\
\hline \multicolumn{5}{|l|}{ Panel B: Welfare maximizing policy } \\
\hline Better admissions's signal & 0.19 & 0.28 & -2.60 & 0.10 \\
\hline Higher tax to finance pub. sch. & 0.39 & 0.65 & 0.78 & 0.23 \\
\hline College tuition to finance pub. sch. & 0.30 & 0.54 & -1.39 & 0.33 \\
\hline More pub. college spots & 0.64 & 2.97 & -2.97 & 0.06 \\
\hline
\end{tabular}

affirmative action under each alternative policy, and Table 3 reports welfare and efficiency gains from welfare-maximizing and efficiency-maximizing affirmative action. The optimal affirmative action policies further improve welfare and increase aggregate output under all four alternative policies, although the magnitudes vary depending on the alternative policy considered.

\title{
5.4.2 Alternative calibrations
}

In this subsection, we run a series of robustness exercises by changing the key calibrated parameters. Our main result that affirmative action should be implemented with focus and moderation holds in all of our robustness exercises. We report the robustness results in Figure C.3 in the Appendix. This figure reports changes in 
aggregate output, intergenerational persistence of earnings and the Gini index for an affirmative action that targets the middle quintile of the income distribution. ${ }^{27}$

We consider an increase in risk aversion $(\sigma=2.5)$, higher marginal impact of educational investment on acquired ability formation $(\gamma=0.9)$ and on human capital $(\psi=0.25)$, as well as more innate ability dispersion $\left(\sigma_{\pi}=0.9\right) .{ }^{28}$ These perturbations to our benchmark calibration affect calibration targets. For example, higher $\gamma$ reduces the fraction of low-income students admitted to public college (bottom $40^{\text {th }}$ percentile) by $11 \%$, and higher $\psi$ increases the marginal benefit of early educational investment and these investments by $13 \%$ on average. Higher innate ability dispersion increases the standard deviation of log earnings by $7 \%$. However, these changes in the calibration do not change our result that affirmative action in college admissions should be implemented with focus and moderation, as displayed in Figure C.3. In all the panels, the intergenerational persistence of earning decreases for a small-scale policy without hurting aggregate output. Hence, our main result that an affirmative action policy should be focused and moderate holds.

\subsection{Evaluating affirmative action in Brazil}

In Brazil, public tuition-free universities are the top-ranked academic institutions, while public education through high school lacks the same performance relative to private schools. Although the majority of students (nearly 90\%) in Brazil attend public schools, only a small fraction are admitted to public universities. In addition, the income distribution of public college students is considerably different from the overall population. For instance, $15 \%$ of the public university spots are occupied by students from the top three percentiles of the income distribution.

In the State of São Paulo, the most populous state in Brazil, 85\% of high school students attend public schools, but only $23 \%$ of University of São Paulo (USP) students attended public school. In terms of income distribution, only $3 \%$ of all its admitted students are in the bottom tercile of the income distribution, while those in the top eight percentiles account for $34 \%$ of admitted students. In Brazil,

\footnotetext{
${ }^{27}$ The pictures are very similar to our benchmark calibration, so we report only results for affirmative action targeting the middle quintile of the income distribution.

${ }^{28}$ In addition to these alternative calibrations, we also solved our model for the optimal affirmative action considering an economy that has no private colleges. We find that affirmative action can still improve efficiency and welfare.
} 
college admissions is major-specific and these differences are more pronounced in some majors. For example, $53 \%$ of students admitted to medical school are in the top eight percentiles of the income distribution. ${ }^{29}$

In 2012, the Brazilian congress approved the major-specific quota policy targeting low-income and public school students. The government is gradually implementing the policy in all federally-sponsored universities and expects it to be fully implemented by 2016 . The law says that $50 \%$ of students admitted to each degree program in Federal Universities must have studied in a public high school. Furthermore, half of those spots are reserved for low-income applicants - i.e., those with a family income less than 1.5 times the minimum wage, who are those in the first quintile of the income distribution. Finally, a fraction of low-income applicants are reserved to non-white, in line with the racial distribution in the university's geographical location. ${ }^{30}$

We use our calibrated model to evaluate the long-run implications of the Brazilian affirmative action policy. We evaluate a policy that allocates $50 \%$ of college spots to applicants from public schools, with half those spot reserved for applicants in the first quintile of the income distribution. We argued in the previous section that affirmative action targeting the bottom quintile is an effective policy to improve welfare and reduce intergenerational persistence of earnings. However, a policy targeting public school applicants has limited effects due to the offsetting equilibrium effects. The Brazilian policy is a combination of these two, as it targets applicants from the bottom quintile as well as those who attended public schools. We find that the Brazilian policy decreases long-run aggregate human capital (output) by $1.23 \%$ and the population-weighted sum of all agents' value function (welfare) by $2.13 \%$. The policy successfully reduces inequality, as measured by the Gini index, by $1.04 \%$. In line with its objectives, the policy promotes educational opportunities by decreasing the intergenerational persistence of earnings by $4.85 \%$.

The Brazilian policy correctly focuses on applicants in the bottom quintile of the income distribution, which is the driving force behind the strong reduction in

\footnotetext{
${ }^{29}$ Data from University Foundation for Vestibular (FUVEST), regarding the 2005 admissions.

${ }^{30}$ Federal law 12.711, August 29th 2012. Although the law was approved in 2012, in 2005 some universities had already started to implement affirmative action policies in a decentralized way. For example, the Federal University of Bahia (UFBA) introduced a similar quota system in 2005. After the implementation, the fraction of students from public schools increased $50 \%$, from $33.8 \%$ to $51 \%$. In some selected majors, it increased more than $400 \%$; for example, in architecture, the fraction of public school students increased from $10.7 \%$ in 2004 to $43.7 \%$ in 2005 .
} 
the persistence of earnings. However, it over-allocates college spots to public school applicants, which makes admissions less efficient, thus reducing aggregate human capital (output). According to our previous analysis of the optimal affirmative action policy, Brazil's policy can be improved. It is possible to further increase welfare, reduce inequality and break the intergenerational persistence of earnings, without hurting aggregate output.

\section{Concluding remarks}

In this paper, we evaluate the effects of different affirmative action policies on welfare, aggregate output, inequality and intergenerational correlation of earnings. We show that such policies directly benefit those in preferentially-treated groups, but that they also change the incentives of all agents in the economy to invest in education. In order to evaluate the effects of these policies, we develop an overlapping-generations model (OLG) and numerically solve for the stationary equilibrium.

Our result is that, when equilibrium effects are taken into account, affirmative action policies targeting low-income applicants are the most effective at increasing aggregate output and improving welfare, while reducing intergenerational correlation of earnings. In our calibrated model, we numerically solve for optimal affirmative action policies based on income. An efficiency-maximizing policy increases aggregate output by $0.41 \%$, while a welfare-maximizing policy increases welfare by $2.44 \%$. We show that affirmative action based on income is a powerful tool for reducing persistence of earnings, as a welfare-maximizing policy decreases intergenerational persistence of earnings by $3.49 \%$. Therefore, affirmative action in college admissions is an effective policy to improve welfare and promote educational opportunities for socially disadvantage students.

It is imperative to include all equilibrium effects in order to evaluate policy implications. If we do not consider changes in educational investment decisions, affirmative action in college admissions is mistakenly assumed to be always beneficial. In such a case, affirmative action would benefit preferentially-treated applicants (e.g., low-income) without affecting the other agents' investment decisions. Therefore, the policy improves the pool of admitted students, thus increasing aggregate output and welfare. In equilibrium, however, the policy makes it harder for non-beneficiaries of the policy to be admitted to college. As a result, if the policy strongly bene- 
fits preferentially-treated students, it disincentivizes the educational investments of non-beneficiaries.

We show that relatively small-scale affirmative action (moderate) targeting lowincome students (focus) is most effective in increasing aggregate output and improving welfare, while also reducing intergenerational correlation of earnings. Affirmative action with focus and moderation is successful because it improves admissions efficiency without disincentivizing educational investment. 


\section{References}

Arcidiacono, P. (2005): "Affirmative Action in Higher Education: how do admission and financial aid rules affect future earnings?," Econometrica, 73(5), 14771524 .

AssunÇÃo, J., And B. FERMAn (2013): "Does affirmative action enhance or undercut investment incentives? evidence from quotas in Brazilian public universities," Working paper.

Becker, G. S., And N. Tomes (1979): "An equilibrium theory of the distribution of income and intergenerational mobility," The Journal of Political Economy, pp. $1153-1189$.

Ben-Porath, Y. (1967): "The production of human capital and the life cycle of earnings," The Journal of Political Economy, pp. 352-365.

Blankenau, W., And X. Youderian (2015): "Early childhood education expenditures and the Intergenerational persistence of income," Review of Economic Dynamics, 18, 334-349.

Chan, J., And E. Eyster (2003): "Does banning affirmative action lower college student quality?," The American Economic Review, 93(3), 858-872.

Coate, S., And G. C. Loury (1993): "Will affirmative-action policies eliminate negative stereotypes?," The American Economic Review, 83, 1220-1240.

Epple, D., R. Romano, and H. Sieg (2008): "Diversity and affirmative action in higher education," Journal of Public Economic Theory, 10(4), 475-501.

FAng, H., AND P. Norman (2006): "Government-mandated discriminatory policies: theory and evidence," International Economic Review, 47(2), 361-389.

Fryer, R., AND G. Loury (2007): "Valuing identity: The simple economics of affirmative action policies," Forthcoming in Journal of Political Economy.

Hickman, B. R. (2010): "Effort, race gaps and affirmative action: A game-theoretic analysis of college admissions," Typescript, University of Iowa Department of Economics. 
— (2013): "Pre-college human capital investment and affirmative action: a structural policy analysis of us college admissions," Working paper.

Holter, H. A. (2015): "Accounting for Cross-Country Differences in Intergenerational Earnings Persistence: The Impact of Taxation and Public Education Expenditure," Quantitative Economics, forthcoming.

INEP (2008): "Resumo Ténico: Censo da Educação Superior 2008," Discussion paper, Ministério da Educação (Brasil), Instituto de Estudos e Pesquisas Educacionais Anísio Teixeira (INEP).

KAPOR, A. (2015): "Distributional Effects of Race-Blind Affirmative Action," Working paper.

Krishna, K., and V. F. Robles (2012): "Affirmative Action in Higher Education in India: Targeting, catch up, and Mismatch," NBER Working Paper No. w17727.

Krishna, K., And A. Tarasov (2013): "Affirmative Action: One size does not fit all," Working paper.

Moro, A., And P. Norman (2003): "Affirmative action in a competitive economy," Journal of Public Economics, 87(3), 567-594.

Restuccia, D., And C. URRutia (2004): "Intergenerational persistence of earnings: The role of early and college education," The American Economic Review, 94(5), 1354-1378.

Solon, G. (1992): "Intergenerational income mobility in the United States," The American Economic Review, pp. 393-408.

Tauchen, G. (1986): "Finite state Markov-chain approximations to univariate and vector autoregressions," Economics letters, 20(2), 177-181.

Veloso, N. G. (2016): "The Impact of College Admissions Policies on The Performance of High School Students," Working paper. 


\section{Appendix}

\section{A Numerical Solution}

The numerical solution of our model is similar to that of Restuccia and Urrutia (2004). We use a Markov approximation for the innate ability process, as suggested by Tauchen (1986), and define a grid over the state space. For a given grade point cutoff and for a given government expenditure on early education, we solve the value and policy functions numerically. We adjust the government expenditure on early education and the grade point cutoff until the government budget is balanced, and the admissions market is cleared. We solve the model doing the following steps:

(i) Guess the value function for the old parents, government expenditure on early education and grade point cutoff;

(ii) Solve for the young parent's value and policy functions, taking as given the old parent's value function;

(iii) Solve for the value and policy functions of the old parent, taking the young parent's value function as given;

(iv) Iterate (ii) and (iii) until convergence;

(v) Guess a distribution over the state space for young parents, and, using the step (iv) young parent policy function, compute the old parent state space distribution. Using the implied distribution and the old parent policy function, compute the young parent state space distribution. Repeat until convergence.

(vi) Lastly, set the government expenditure on early education and the grade point cutoff to balance the government budget and clear the admissions market. Using these new values, repeat the previous steps until convergence.

We compute the efficiency-maximizing affirmative action policy by choosing the bonus points of each income quintile that maximizes aggregate output. The welfaremaximizing policy achieves the highest welfare, without decreasing aggregate output. We construct an initial educated guess for the numerical optimization by running a grid search varying bonus points by 2.5 p.p. from $0 \%$ to $15 \%$. In the numerical 
optimization, policy bonus points are a multiple of 0.5 p.p. in order to prevent the procedure from becoming computationally intense.

\section{B Equivalence between quotas and bonus points}

Proposition 1. For every equilibrium with quotas in the admissions process, there is an equilibrium with bonus points and no quota with the same allocation. The converse is also true: for every equilibrium with bonus points in the admissions process, there is an equilibrium with quotas and no bonus points with the same allocation.

\section{Proof:}

First, let us take an equilibrium in which bonus points of $p_{\text {bonus }}$ are implemented for a certain treatment group. Let $\bar{q}^{*}$ and $g^{*}$ be the grade point cutoff and the government spending on early education in such an equilibrium. Furthermore, let $S P_{p t}$ be the fraction of public college students in the preferential treatment group.

For a given acquired ability level $\hat{\pi}$, a student in the preferential treatment group will be admitted to a public college with a probability given by

$$
q^{\text {bonus }}\left(\hat{\pi}, \bar{q}^{*}\right)=1-\Phi\left(\frac{\log \left(\bar{q}^{*}\right)-\log (\hat{\pi})-\log \left(p_{\text {bonus }}\right)}{\sigma_{P}}\right)
$$

If the students is not in the treatment group, her probability of admission is

$$
q^{\text {no bonus }}\left(\hat{\pi}, \bar{q}^{*}\right)=1-\Phi\left(\frac{\log \left(\bar{q}^{*}\right)-\log (\hat{\pi})}{\sigma_{P}}\right)
$$

To find the equilibrium with quotas, take the same allocation, but there will be two grade point cutoffs: one for the quota $\left(\bar{q}^{\text {quota }}\right)$ and another for the no-quota student $\left(\bar{q}^{\text {no quota }}\right)$. These cutoffs are defined as $\log \left(\bar{q}^{\text {quota }}\right)=\log \left(\bar{q}^{*}\right)-\log \left(p_{\text {bonus }}\right)$ and $\log \left(\bar{q}^{\text {no quota }}\right)=\log \left(\bar{q}^{*}\right)$.

Using these cutoffs, the parent's maximization problem is exactly the same. Then, this allocation, along with the government expenditure on early education and the grade cutoffs, constitute an equilibrium. Similarly, from an equilibrium with quotas, the grade point cutoff gap between the preferential treatment group and the other students can be used to get the necessary bonus points to construct an equilibrium with bonus points that generates the same allocation. 


\section{Tables and figures}

Figure C.1: Investments and Innate Ability: AA 20 income percentile

This figure reports the implications of affirmative action targeting low-income applicants $\left(20^{\text {th }}\right.$ income percentile). Panel A plots the average innate ability among students attending public college against the affirmative action bonus points. Panel B plots the average investment in early education among students attending public college against the affirmative action bonus points.

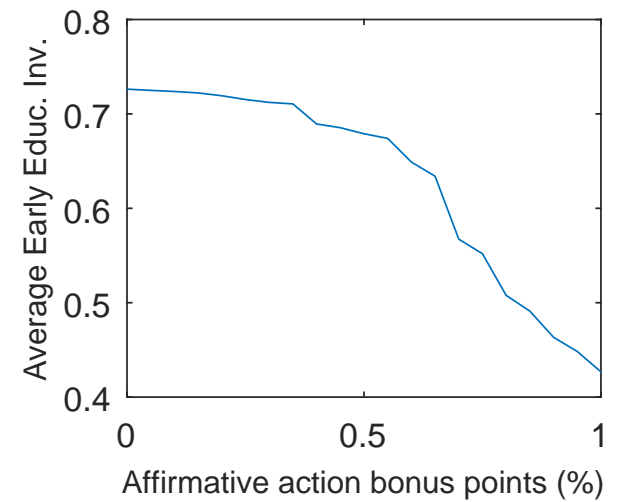

(a) Average $e$ in public college

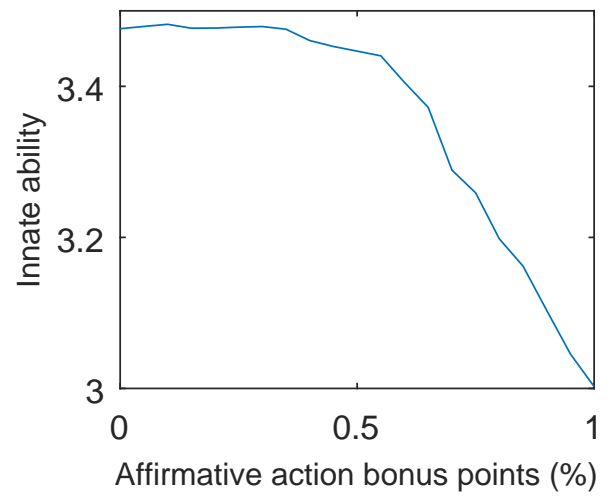

(b) Average $\pi$ in public college

Figure C.2: Investments and Innate Ability: AA $20^{\text {th }}$ income percentile

This figure reports the implications of affirmative action targeting low-income applicants $\left(60^{\text {th }}\right.$ income percentile). Panel A plots the average innate ability among students attending public college against the affirmative action bonus points. Panel B plots the average investment in early education among students attending public college against the affirmative action bonus points.

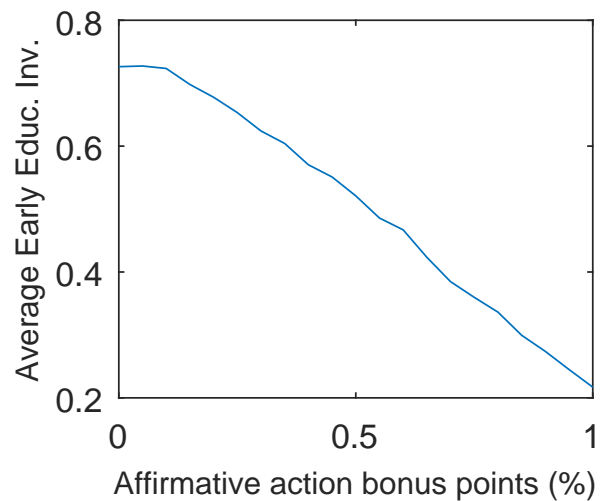

(a) Average $e$ in public college

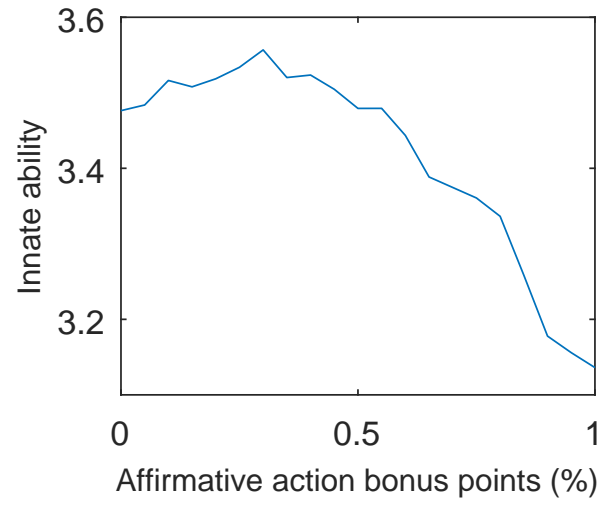

(b) Average $\pi$ in public college 


\section{Figure C.3: Robustness}

Each panel represent a distinct robustness exercise in which we change key calibration parameters. Panel (a) considers a higher risk aversion $(\sigma=2.5)$. Panel (b) reports the effects of a higher marginal impact of educational investment on acquired ability formation $(\gamma=0.9)$. Panel $(c)$ considers a higher marginal effect of investment on human capital $(\psi=0.25)$. Panel $(\mathrm{d})$ considers a higher dispersion in innate ability $\left(\sigma_{\pi}=0.9\right)$. Each panel reports changes in aggregate output, intergenerational persistence of earnings and Gini index for an affirmative action that targets the middle quintile of the income distribution. These changes are plotted against the left axis and include all equilibrium effects. Additionally, we plot the fraction of preferentially-treated applicants admitted to college against the right axis.

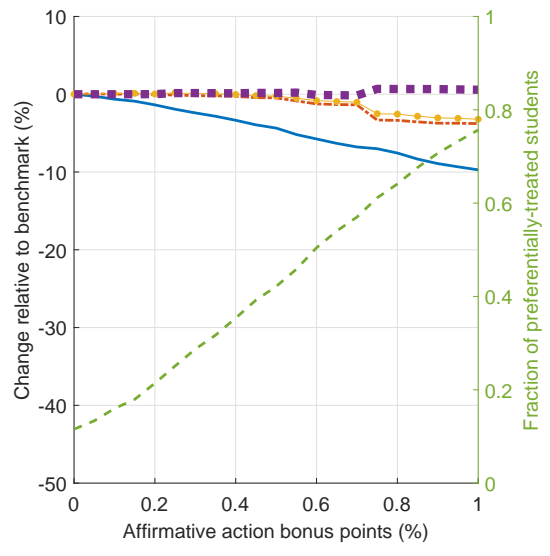

(a) Higher risk aversion, $\sigma$

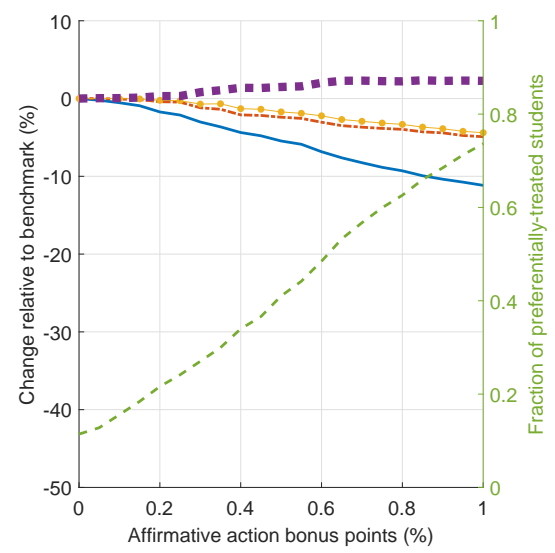

(c) Higher $\psi$

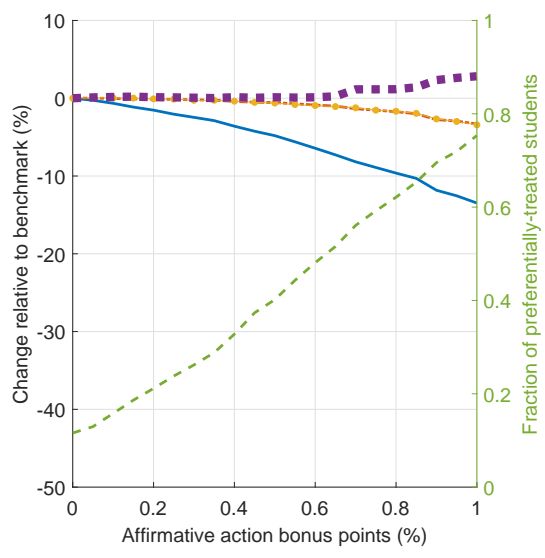

(b) Higher $\gamma$

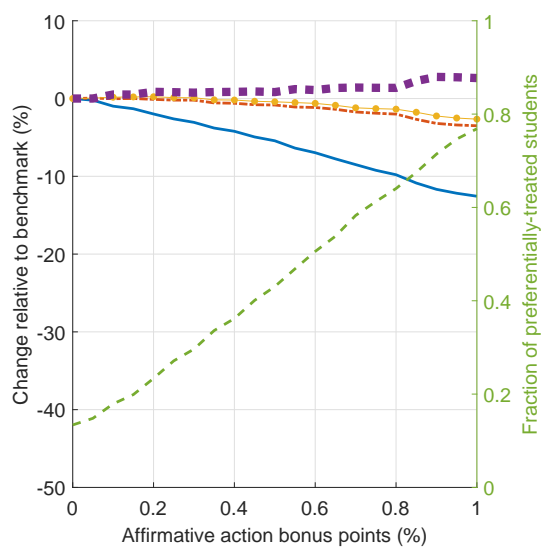

(d) Higher innate ability dispersion, $\sigma_{\pi}$ 